\title{
PARAMETRIC SOLUTION OF LATERAL BUCKLING OF SUBMARINE PIPELINES
}

1. Indranil Guha

$\mathrm{PhD}$ Candidate

University of Western Australia

35 Stirling Highway, Crawley

WA 6009, Australia

Email:guhanil@gmail.com

2. David J. White

Professor of Infrastructure Geotechnics

Engineering and the Environment

University of Southampton, Highfield, Southampton, SO17 1BJ, UK

Also affiliated with the University of Western Australia

Email: david.white@soton.ac.uk

3. Mark F Randolph

Professor

Fugro Chair in Geotechnics, Centre for Offshore Foundation Systems

University of Western Australia

35 Stirling Highway, Crawley

WA 6009, Australia

Email: mark.randolph@uwa.edu.au 


\begin{abstract}
Lateral buckling analysis of on-bottom submarine pipelines is of particular interest in the offshore industry due to the complexities involved in the analysis, and the potential design efficiencies that can be unlocked. Classical buckling theories by previous researchers and recent joint industry projects provide a basis for estimation of the critical buckling load of a straight, or in some cases imperfect, pipe on either a rigid or elastic seabed. However, systematic solutions for the combined effects of nonlinear soil properties and the as-laid geometry - specifically the out-of-straightness - on the buckle initiation behaviour have not been developed previously.

This paper reports an investigation of the buckling problem of an imperfect (non-straight) onbottom pipeline subjected to axial compressive loading. The seabed was modelled with lateral and axial elastic, perfectly plastic, springs to idealise the load-displacement behaviour of the soil and the pipe was modelled with pipe elements. Buckling was performed by a displacement controlled finite element method with the modified RIKS algorithm that is available in the commercial software ABAQUS. This numerical tool was used to develop a parametric solution for the present problem in terms of the various pipe material and geometry parameters and the lateral and axial pipe-soil interaction parameters. In particular, the influence of the magnitude and stiffness of the lateral pipe-soil response was investigated, highlighting the sensitivity of the pipeline response to the geotechnical inputs. The results have been synthesised in a generic non-dimensionalised design chart to estimate the buckling load, valid for the range of inputs covered by the parametric study.
\end{abstract}

Keywords: submarine pipelines, buckling, soil response, out-of-straightness, RIKS 


\section{INTRODUCTION: BUCKLING OF OFFSHORE PIPELINES}

With the depletion of onshore and shallow offshore hydrocarbon reserves, the present oil and gas industry is moving into the deeper sea. Deep sea developments generally include a number of wells linked by flowlines, in addition to an export pipeline to onshore production facilities. Deepwater pipelines are laid on the seabed and are usually left unburied. In operation they are subjected to cycles of high temperature and high pressure. This raises the possibility of on-bottom buckling or incremental axial displacement (walking) of the pipelines [1].

Allan [2] proposed a solution for the critical buckling load for vertical mode for a thin strip with an imperfection at the centre under axial compressive load on a flat bed. Little further work has been done to modify or include other parameters into the simple formula given by Allan [2].

Hobbs [3-4] solution for a straight pipeline is still considered to be the design guideline for buckling phenomena related to on-bottom pipelines. Both upheaval and lateral critical buckling loads had been determined and expressed as a function of the length of the buckle. For upheaval buckling it was assumed that the bending moment and slope at the lift-off point is zero. For lateral buckling the lateral resistance is assumed fully mobilised and the zero slope condition at the end of the buckle is replaced by a shear force condition there. The buckling solutions proposed by Hobbs was based on the Kerr's [5-6] studies on the buckling of railway tracks, assuming a rigid foundation with a constant frictional resistance.

Maltby \& Calladine [7] extended Hobbs' solution for a straight pipe on a rigid seabed by including an initial out of straightness of the pipe. They related the critical buckling load to the central height (or imperfection) of the pipe above the seabed. They also proposed a solution for lateral buckling of an imperfect pipe on a seabed with a non-linear mobilisation of lateral resistance. More details of their work has been provided in the following sections.

Croll [8] derived the critical vertical buckling load of a straight pipe on flat seabed, imperfect pipe on a point protrusion support and imperfect pipe on a continuous support. Similarly, Tran \& Taylor [9] expressed the critical upheaval buckling load of an imperfect pipe on a continuous support, on an isolated prop support and on a filled-prop support as a function of Hobbs’s [4] solution. Hetényi [10] proposed a critical buckling load solution for a bar under simultaneous axial and transverse loading. In that model the bar was considered to be straight and lying on an elastic foundation under axial compression. 
Joint industry projects (JIPs) such as the previous HOTPIPE and subsequent SAFEBUCK projects developed guidelines addressing the buckling phenomena related to HT/HP pipelines [11-12]. In these projects the buckling of subsea pipelines subjected to internal pressure and temperature changes was investigated. SAFEBUCK project outlined a design approach that addresses the inherent uncertainties of the lateral buckling problem in a safe and quantifiable way [12]. Submarine pipelines that are vulnerable to Euler buckling in the horizontal / lateral plane are considered in this project. Hobbs [3-4] was adopted to provide analytical solution of lateral buckling and thereafter numerical solution was provided to verify the analytical model.

A key step during the design of a HP/HT pipeline is to assess whether the pipeline will be susceptible to on-bottom buckling. If buckling is likely, then the design must ensure that buckles will form safely and reliably at a suitable spacing to absorb the expansion, without overstressing the pipeline or leading to fatigue. A key element of this analysis is assessment of the critical load at which buckling will occur. This load is then compared with the expansion forces created by the constrained expansion created by changes in pressure and temperature.

These solutions are simple and easy to use without any complexity of the soil-pipe interaction. However, in practice the geotechnical parameters play a role, along with the as laid geometry and pipe material, in the buckling behaviour of submarine pipelines. This study evaluates the effects of as laid geometry of the pipe, ultimate lateral and axial soil resistances and pipe-soil stiffness on the critical buckling load. At the end an attempt is made to include all the relevant parameters into a single correlation, which then can be used to predict the buckling load required.

Table 1 summarises the assumptions and expressions for the critical buckling load of submarine pipelines given by various researchers over the last two decades. The aim of this study is to provide insight into how the axial and lateral components of pipe-soil stiffness and limiting resistances affect the lateral buckling response, and to derive new expressions for the critical buckling load that take account of these components of pipe-soil interaction.

\section{PROBLEM DEFINITION AND NOTATIONS}

Buckling analysis of pipelines has created considerable interest in the past due to the complexities involved in the analysis. JIP projects [11-12] have provided a general overview of buckling phenomena and solutions derived from classical theory. However, the separate effects of soilpipeline interaction, pipe material and geometry on the buckling initiation load were not properly identified and discussed. This paper presents results of detailed numerical analyses carried out to 
investigate the effects of geotechnical and non-geotechnical parameters on the critical lateral buckling load of submarine pipelines. The analyses were carried out in three steps. In the first step, the pipe response was investigated using elastic-plastic lateral springs attached along a pipe with a lateral out-of-straightness (OOS) but without any initial stress. The numerical solutions were found to match theory well, although it was found that the classical theories do not allow for the effect of lateral soil stiffness. Hence, the classical solutions were extended, based on the results of the analyses, to express the critical buckling load non-dimensionally as a function of a soil stiffness factor. In the second set of analyses, axial soil elements were introduced into the previous analyses but the pipe was considered without any initial stress. This allowed another non-dimensionalised expression of critical buckling load to be formulated, incorporating factors representing the axial and lateral soil stiffnesses and ultimate resistances, in addition to the initial OOS of the pipeline for a range of pipe parameters. The third set of analyses were the extension of the second set but with the initial stress in the pipe.

The pipe was defined by diameter, $D$, thickness , $t$, Young's modulus, $E$, Yield stress, $\sigma_{y}$, with a OOS, $\triangle$, nominal length of the OOS, $L$, and the bending rigidity, $E I$ and axial stiffness, EA can be calculated. The loads per unit length on the pipeline are defined as horizontal load $H$, parallel to the y-axis and axial load $F$ parallel to the x-axis (see Figure 1). Likewise the displacements along the $x$ and $y$ axes are $\delta_{\mathrm{x}}$ and $\delta_{y}$, respectively as shown in Figure 1 . The stiffnesses in the three directions $k_{v}, k_{y}$ are defined as load (per unit length) per unit displacement, so with typical units of $\mathrm{kN} / \mathrm{m}^{2}$ or $\mathrm{kPa}$, and are expressed as $k_{y}=H / \delta_{y}$ for horizontal/lateral direction and $k_{x}=F / \delta_{\mathrm{x}}$ for axial direction. The output of the analyses was the critical buckling load and expressed as $P_{c r}$. The dimensional analysis of buckling is discussed in the following section.

\section{DIMENSIONAL ANALYSIS}

The aim of this study is to provide generic design charts expressing the resulting critical buckling load of the pipeline as a function of the various input parameters. Therefore, dimensional analysis is a particularly suitable starting point for this study. Although this kind of analysis alone does not usually lead to a complete solution of the problem, it increases the understanding by laying the foundation of design of numerical and experimental simulations [13].

A summary of the various input parameters considered for the analyses is provided in Table 2, along with the main output parameter, which is the critical buckling load, $P_{c r}$. There are eight input variables, but only two dimensional outputs: buckling load $(\mathrm{kN})$ and nominal length of the 
OOS (m). As such, the output may be expressed, non-dimensionalised, as a function of six independent dimensionless groups. Many different combinations of the input variables are available, but the underlying dimensions of this problems are length and force. Therefore, here it has been decided to use the bending rigidity EI, as standard force and a length that approximates the pipeline diameter $D$. For pipes of moderate wall thicknesses, the nominal diameter of the pipe may be approximated as

$$
D \approx \sqrt{\frac{8 E I}{E A}}
$$

For the normalisations used in the paper $D$ refers to the external diameter and the true (exact) values of $E I$ and $E A$ have been used.

The other length quantities are the out of straightness parameter $\Delta$, and the nominal length $L$ of the out of straight section of the pipeline. A more precise definition of $L$ is provided later, with respect to the actual pipeline profile adopted in the numerical analyses. These length quantities may be normalised by the approximate pipeline diameter, although it is rather more convenient from an application perspective to consider $\Delta / L$ (equivalent to $\Delta / D$ divided by $L / D$ ), rather than $\Delta / D$.

The critical buckling load may then be expressed as

$$
\frac{P_{c r} \Delta^{2}}{E I}=g\left(\frac{\Delta}{L}, \frac{H \Delta^{3}}{E I}, \frac{\Delta}{\sqrt{8 E I / E A}}, \frac{k_{y}}{H} \sqrt{\frac{8 E I}{E A}}, \frac{F}{H}, \frac{k_{x}}{F} \sqrt{\frac{8 E I}{E A}}\right)
$$

This expression is a generalisation of the buckling solution provided by Maltby \& Calladine [7] for upheaval buckling of a pipe of weight (per unit length) $W$ resting on a rigid seabed. Here, where lateral buckling is being considered, the lateral resistance $H$ replaces the pipeline weight. In addition, the pipe cross-sectional rigidity $E A$, axial resistance $F$ and corresponding axial and lateral pipe-soil stiffnesses are considered. Also, elastic slips in the lateral and axial directions were considered by dividing elastic stiffnesses by the corresponding forces. These length quantities may be normalised by the approximate pipeline diameter.

Before starting the numerical analyses it is useful to discuss about the theory proposed by Maltby \& Calladine [7] . They described an experimental study of some aspects of upheaval buckling of buried pipelines by small-scale model. Various theories of upheaval buckling with rigid base were reviewed in their study and the experimental observations on the growth of initial imperfection in 
the pipe under constant increasing axial load, and also the formation of unstable buckles were in good agreement with the findings of Tvergaad and Needleman [14] on railway track.

For this analyses it is helpful to consider the Maltby \& Calladine [7] buckling solution, as summarised in Table 1, replacing the pipe weight by the limiting lateral resistance of the soil. They gave the critical load for a straight pipe resting on a rigid (smooth) seabed as

$$
P_{c r}=3.96 \sqrt{\frac{H E I}{\Delta}}
$$

with the corresponding nominal length of the OOS expressed as

$$
L=4.51\left(\frac{\Delta E I}{H}\right)^{1 / 4}
$$

Rearranging equation (3) gives

$$
\frac{P_{c r} \Delta^{2}}{E I}=3.96 \sqrt{\frac{H \Delta^{3}}{E I}}
$$

And rearranging equation (4) gives

$$
\frac{\Delta}{L}=\frac{1}{4.51}\left(\frac{H \Delta^{3}}{E I}\right)^{1 / 4} \text { or } 4.51 \frac{\Delta}{L}\left(\frac{H \Delta^{3}}{E I}\right)^{-1 / 4}=1
$$

The boundary conditions in the Malty \& Calladine [7] solution led to a constraint on the magnitude of the nominal length of the out-of-straightness, $L$ in terms of $H$ and $E I$. However, in the more general analysis presented here, the initial length $L$ of the out of straight section of pipeline is an independent input variable, although also reflects closely the length of the buckle that transpires.

An expression for the critical buckling load that reflects both $H$ and $L$ may be obtained by dividing the right hand side of equation (5) by some power, $n$, of equation (6), to give

$$
\frac{P_{c r} \Delta^{2}}{E I}=3.96\left(\frac{H \Delta^{3}}{E I}\right)^{1 / 2}\left(\frac{H \Delta^{3}}{E I}\right)^{n / 4} \cdot\left(4.51 \frac{\Delta}{L}\right)^{-n}
$$

The relative contributions of $H \Delta^{3} / E I$ and $\Delta / L$ may be 'balanced' by taking $n=2 / 3$, which results in a final expression for the critical buckling load of 


$$
\frac{P_{c r} \Delta^{2}}{E I}=1.45\left(\frac{\Delta}{L}\right)^{-2 / 3}\left(\frac{H \cdot \Delta^{3}}{E I}\right)^{2 / 3}
$$

Justification for such balancing of the contributions from $H \Delta^{3} / E I$ and $\Delta / L$ is provided later in light of the numerical analysis results.

\section{METHODOLOGY}

To investigate the buckling behaviour of submarine pipelines, and an appropriate form for the generalised relationship of equation (2), finite element analysis was performed using the commercially available software ABAQUS Version 6.9 [15] .

The numerical analysis explores the buckling of an imperfect (non-straight) on-bottom pipeline subjected to axial compressive loading. The seabed was modelled with lateral and axial elastic, perfectly plastic, springs to idealize the load-displacement behaviour of the soil, and the pipe was modelled with pipe elements.

The dimensional analysis was carried out in three stages. In the first stage only lateral springs were used, with the axial pipe-soil response assumed frictionless. In the second stage axial springs were introduced along with the lateral springs. In both those stages, the out-of-straightness of the pipe was simulated without incorporating any internal stresses in the pipe wall. A third set of analyses were then undertaken where the pipe was 'forced' into the out-of-straight shape, giving rise to internal stresses in the pipe. Note that for the first, so-called "without-axial-spring” stage, the general expression for the non-dimensionalised buckling load can be simplified to

$$
\frac{P_{c r} \Delta^{2}}{E I}=g\left(\frac{\Delta}{L}, \frac{H \Delta^{3}}{E I}, \frac{\Delta}{\sqrt{8 E I / E A}}, \frac{k_{y}}{H} \sqrt{\frac{8 E I}{E A}}\right)
$$

The fixed input parameters which were used to calculate the range of input parameters are tabulated in Table 3, and introduced in the following sections.

\subsubsection{Out-of-straightness (OOS)}

The as laid condition of a pipeline generally includes a degree of out-of-straightness (OOS) in the horizontal and vertical planes, either due to the natural form of the seabed or as a deliberate design approach (referred to as 'snake lay') during pipelay. Assuming an initial stress free cosine or sine curve for the nonlinear shape of the as laid pipeline will generally suffice for predictions of the 
buckling load. The initial stress free shape considered by Tvergaard \& Needleman [14] was modified slightly for the analyses.

The shape of the initial geometry is shown in Figure 2 and is given by

$$
y=\Delta\left[\exp ^{-3\left(\frac{x-x_{0}}{L_{s}}\right)^{2}} \cdot \cos \left(\frac{\left(x-x_{0}\right) \pi}{L}\right)\right]
$$

where $\Delta$ is the maximum out of straightness, $L_{s}$ controls the value of the minor buckles to either side of the major (central) buckle of length $L$ ( length of the OOS section). The quantity $x_{0}$ corresponds to the distance of the centre of the buckle from the loaded end of the pipe, with $x_{0}$ taken as $2 L$. Note that the OOS section of the pipeline was taken deliberately close to the axially loaded end of the pipeline rather than at the middle, to minimise the reduction in axial load between the end of the pipe and the buckle (for analyses that included axial springs). This helped to localise the buckle in the region of OOS, where the axial load was high. In reporting results, actual values of $P_{\text {cr }}$ are reported from the centre of the buckle, together with actual values of $\Delta$ and $L$. The $\Delta / L$ ratio was varied from 0.01 to 0.05 [16] . This range represents typical levels of out-of-straightness created by the lay process and natural seabed undulations.

\subsubsection{Lateral and axial soil response: stiffness and limiting resistance}

The adopted ranges of lateral and axial soil resistance span typical field conditions on soft clay. The values of lateral soil resistance, $H$, span a range of $>1000$, while the axial resistance, $F$, spans a range of $>4000$ (the ratio $F / H$ varies by a factor of $\sim 3$ ) (Table 3). A mean estimate of the stiffness and limiting resistance in the lateral and axial directions was made using the parameters given in Table 4, and calculation methods based on elastic and plasticity [17-19] . These typical values were then extended to create the wider range spanned by the parametric study.

The axial pipe-soil stiffness is given as [17]

$$
k_{x}=m D \sin \theta_{D}
$$

where $k_{x}$ is the axial soil stiffness, $m$ is the constant of shear modulus ( $G=m z, z$ is the depth below the pipe), and $\theta_{D}$ is the embedment angle of the pipe as discussed in the previous paper. The axial elastic stiffness, $k_{\mathrm{x}}$ span a range of 0.04 to $>200 \mathrm{kN} / \mathrm{m}^{2}$ was considered here.

The limiting value of the axial force is 


$$
F_{\text {passive }}=\alpha \mathrm{s}_{u_{-} \text {seabed }} D \theta_{D^{\prime}}
$$

where $F_{\text {passive }}$ is the ultimate axial frictional resistance of the soil per unit length, $\alpha$ is adhesion factor, undrained shear stress varies with depth $z$ as $s_{u_{-} \text {seabed }}=k z, D$ is the diameter of the pipe, $\theta_{D}$ is the subtended contact angle [20].

The lateral pipe-soil stiffness, ky was estimated by dividing the ultimate lateral resistance, $\mathrm{H}$, by elastic slip, $\delta y$. For this study $\delta y$ in the range of $0.05 \mathrm{D}$ to $0.5 \mathrm{D}$ was considered. As highlighted in the paper Guha et al [17] that lateral and vertical stiffnesses predicted numerically are rather higher. The higher values for homogeneous soil modulus may be attributed, at least partly, to the limited layer modelled numerically. Therefore, a range of $0-20 \%$ was proposed in the paper for vertical and lateral elastic stiffnesses. Therefore, a slightly higher value of $\mathrm{kx} / \mathrm{ky}=0.7$ was adopted in the present paper.

\subsubsection{Numerical method}

To analyse the problem of lateral buckling of submarine pipelines static and dynamic numerical analyses are used by the pipeline engineers. However, in ABAQUS three finite element calculation algorithms i.e. static, RIKS [21] and dynamic methods are available to carry out lateral buckling. Static method uses an incremental Newton-Raphson solution technique. But for high nonlinear problem like lateral buckling, the static method is less preferable due to numerical convergence problem. Comparison of these three methods were presented by previous researchers ([22] - [24]), reveal that three methods are in good agreement to predict the peak buckling load. Since the aim of this paper is to predict the peak buckling load rather than post-buckling analysis, dynamic solution would not provide any additional advantages relative to RIKS method. Therefore, to analyse the problem of buckling associated with material nonlinearity and geometric nonlinearity prior to buckling an advanced method such as the Riks algorithm [21] is used in this paper. The Riks method uses the load magnitude as an additional unknown; it solves the load and deflection simultaneously. Geometrically nonlinear static problems sometimes involve buckling or collapse behaviour, where the load-deflection response shows a negative stiffness and the structure must release strain energy to remain in equilibrium. The Riks algorithm allows for the complete loaddeflection curve to be determined including a reversal of load path. Therefore with this method it is possible to study an instability phenomenon such as bifurcation and snap-through buckling and obtain a complete solution of the post-buckling response. This method is used for cases where the loading is proportional, that is, where a single scalar parameter governs the load magnitude. The 
advantage of the method is that the solution is viewed as the discovery of a single equilibrium path by the loading parameters and the nodal variables. The elegant solution comes by tracing the equilibrium path, as far as required.

For nonlinear buckling analysis modified Riks method is very popular. Torselleti et al. [25] , as part of the Hotpipe project, carried out FE analysis of submarine pipeline resting on flat seabed with ABAQUS. They employed RIKS method to compare the analytical solution with their numerical results for initial imperfection and pipe material properties. Sriskandarajah et al. [22] employed arc-length method to investigate the lateral buckling influenced by the lay induced imperfection.

In risk based design and reliability analysis of submarine pipelines subjected to global buckling, FE analyses with ABAQUS was also very popular [26, 27] with beam or pipe elements and were mainly used for structural analysis of long pipelines for numerical advantages [23-30]. The details of beam and pipe elements and the pipe-soil interaction are discussed in the following sections.

\subsubsection{Pipe element as pipe model}

The pipe elements in ABAQUS such as PIPE21, PIPE22, PIPE31, PIPE32, etc and their hybrids are available with hollow, thin-walled, circular section. The hoop stress caused by internal or external pressure loading in the pipe is included. The main purpose of these is to provide for the subsequent difference in yield when a point in the section is subjected to axial tension or compression stress due to its nonzero hoop stress component causing an asymmetry in the section's response to inelastic bending. The hybrid pipe elements such as, PIPE31H, PIPE32H, etc are used where it is difficult to compute the axial and transverse shear forces in the beam by the FE displacement method. This kind of problems of arises in geometrically nonlinear analysis when the element undergoes large rotations and is very rigid in axial and transverse shear deformation, such as flexible long pipe or cables. The hybrid elements use a more generalised formulation in which the axial and transverse shear forces in the elements are included, along with the nodal displacements and rotations, as primary variables. Figure 3 shows various types of beam elements available in ABAQUS element library. However, two-node linear pipe element PIPE31H was selected as the appropriate element for this kind of geometric nonlinear analysis due to the option of applicability of internal and external pressure for these elements for future research where study can be under taken to investigate the effect of internal and external pressure on the buckling response [23, 27, 28]. 


\subsubsection{Pipe-soil interaction model}

Traditionally, the buckling of submarine pipelines and the seismic fault crossing effect on buried pipelines idealises soil behaviour using discrete springs to model the pipe-soil interaction based on the concept of subgrade reactions, typically a Winkler-beam style representation of the pipeline. In that model the soil is represented as series of independent springs attached to the nodes of the pipeline. An elasto-plastic spring is generally used to idealise the force-displacement response at the pipe surface. The spring relationships in all the three direction are defined by the maximum force per unit length at the soil pipe interface and the ultimate mobilization displacement. The force-displacement model considered, for all the three directions is defined in the section below. For nonlinear structural analysis pipe soil interaction (PSI) and spring elements are widely used.

The axial and lateral soil pipe interaction was modeled with nonlinear springs (SPRING1) available in ABAQUS, which link each node to a fixed reference point (the ground). The nonlinearity of the springs was defined separately in the input code. The relative displacement across a SPRING element is the $i^{\text {th }}$ component of displacement of the spring's node and can be given by:

$$
\Delta u=u_{i}
$$

where $i$ is defined in the spring input code and is in the local direction of the model. In ABAQUS lateral and axial springs are directly oriented towards the global coordinates. In this scenario if the pipe element is deformed in the global $\mathrm{x}$-axis, the axial soil stiffness will contribute to both axial and lateral stiffness component. At the same time lateral soil stiffness may affect the axial component and lateral component. Therefore, special computing may be employed to eliminate this issue [31] . However, to predict the peak buckling load in the pipe this issue has minimum impact. Therefore, for the simplicity purposes this has been ignored here.

\subsubsection{Model discretization and boundary conditions}

To carry out FE analysis the pipe was idealised as an elastic-plastic beam resting on a nonlinear foundation with one end on the roller and the other end was pinned. At the roller end a displacement was given which idealises the compressive load in the axial direction. A lateral imperfection was deliberately introduced into the pipe to investigate the effect of OOS on the critical buckling load. The whole length of the pipeline was divided into small elements of approximately 1 metre length and at each node of the element bilinear springs were attached, which 
represents the soil restraints in the lateral and axial directions. The effect of element size was also investigated by changing the element size and thereby changing the number of springs.

\section{CASE STUDY}

Based on the model described in the above sections a simple case study was performed to check the sensitivity of the model in a series of buckling analyses. In the first case the axial springs were not attached and the OOS was considered to be initially stress free. Only lateral springs were attached to analyse the behaviour of lateral buckling during an axial compressive loading. The effects of temperature, pressure and external loads were incorporated by displacing the end of the modelled section of pipe axially in compression.

\subsubsection{Example analyses - effect of $O O S$}

With the model discussed in the above section an example analysis was carried out to check the effect of input parameters on the expected outcomes. For this example a pipe with $D=0.152 \mathrm{~m}$ $\left(6^{\prime \prime}\right)$ was considered with $D / t$ ratio as 30.3 and $\sigma_{y} / E$ as 0.002 . The pipe has a bending rigidity, EI of 1.24 $\mathrm{MNm}^{2}$. A bi-linear soil model was considered with normalised limiting lateral resistance, $H \Delta^{3} / E I=4.24 \times 10^{-05}$ and elastic stiffness, $k_{\mathrm{y}} / H \sqrt{ } 8 E I / E A=16.66\left(H=424 \mathrm{~N} / \mathrm{m}\right.$ and $\delta_{\mathrm{y}}=0.008$ $\mathrm{m})$. The ratio of $\Delta / L$ was varied from 0.01 to 0.05 .

Axial load-displacement curves for various $\Delta / L$ ratios are compared in Figure 4 . For smaller OOS the peak buckling load is higher and the instability is more prominent. With increasing OOS the axial load-displacement response becomes more ductile. The summary of peak load is plotted as shown in Figure 5. It depicts the variation of peak buckling load with OOS. The peak load at $\Delta / L$ $=0.01$ is 3.5 time higher than the peak load at $\Delta / L=0.05$. With increasing $\Delta / L$ ratio the load required for buckling decreases. Therefore, it agrees with the previous findings that OOS tends to reduce the critical buckling load as presented by others [7, 8, 9 \& 23].

The lateral offset of the midpoint of the buckling evolves as the axial load increases, as shown in Figure 6 . With increasing $\Delta / L$ ratio, the lateral offset of the midpoint of the buckle increases significantly. Axial load is plotted in the x-axes and the lateral displacement of the midpoint of the buckle is plotted in the y-axes intentionally to show the effect of load on lateral offset.

Figure 7 shows the lateral friction distribution at the buckling initiation along the length of the pipeline for $\Delta / L=0.01$ to 0.05 . The ultimate lateral resistance was fully mobilised through the 
central lobe prior to the onset of buckling for $\Delta / L>0.01$, and for $\Delta / L=0.05$ the ultimate resistance was also fully mobilised in the secondary lobes when buckling occurred. These results show the significance of initial soil condition and effect of $O O S$ on the buckle response.

The comparison between the initial shape and the corresponding displaced shapes of the buckles at the peak load are shown in Figure 8. A smaller OOS requires a larger load to mobilise the elastic limit. Figure 8 show that a larger $O O S$ is more prone to buckle and the corresponding lateral displacement is higher for smaller OOS. It is evident from Figure 9 that the lateral offset of the pipe is very low $(0.0093 \mathrm{~m})$ for $\Delta / L=0.01$ when buckling occurs, and has only just exceeded the elastic limit within the lateral force-displacement response. However, the lateral displacement at which buckling occurs increases with increasing OOS. For $\Delta / L=0.05$ the offset of the midpoint of the buckle at peak load is 47 times higher than that for $\Delta / L=0.01$.

\subsubsection{Example analyses - effect of soil resistance}

To show the effect of lateral limiting friction on the peak load, FE results for three different limiting lateral resistances $(H=100,200$ and $424 \mathrm{~N} / \mathrm{m})$ were compared. Figure 10 illustrates the influence of the lateral limiting resistance on the peak load of the middle node. It is evident that the buckling initiation is significantly influenced by the lateral limiting residence. With reducing limiting lateral resistance from $424 \mathrm{~N} / \mathrm{m}$ to $100 \mathrm{~N} / \mathrm{m}$ ( $\sim 4$ times) the peak load reduce to 2 (slightly higher than ) times. At the time for a lower OOS the limiting lateral soil resistance has greater impact on peak buckling than for a higher OOS. This is due to higher OOS gives more ductile response during buckling.

The value analytical solution proposed by Malty \& Calladine [7] for $\mathrm{H}=424 \mathrm{~N} / \mathrm{m}$ was plotted on the same graph (dotted line) to compare between analytical and FE solutions. FE results are lower than the analytical results because of the initial assumptions in the analytical modelling; (1) analytical solution considered a fully mobilised lateral limiting friction and, (2) In the FE solution the initial shape similar to mode 3 (of Hobbs solution) was considered predicted by equation (10) whereas for the analytical solution mode 1 (of Hobbs solution) was considered by Malty \& Calladine [7].

To show the effect of lateral soil stiffness (or reverse of elastic slip) on the peak load a series of analyses were carried out for elastic stiffness parameter of the lateral spring, $k_{\mathrm{y}}$ ranging between $0.5-5 \mathrm{kN} / \mathrm{m}^{2}$. This was achieved by varying the elastic slip, $\delta_{\mathrm{y}}$ between $0.05 \mathrm{D}-0.5 \mathrm{D}$ for $\mathrm{H}=$ 
$424 \mathrm{~N} / \mathrm{m}$ and $E I=1.24 \mathrm{MNm}^{2}$. Figure 11 depicts the effect of elastic slip on the peak load. The elastic slip was normalised by the diameter of the pipe ( $0.152 \mathrm{~m}$ or 6 ”). With increasing elastic slip (decreasing elastic stiffness) of the soil the peak load reduces [23].

Before starting the parametric study for 'without axial', 'with axial and without initial stress' and 'with axial and with initial stress' cases a simple graph was plotted to show the effect of these three cases on the normalised peak buckling load. For this analysis similar input parameters were chosen as above only axial soil resistance was introduced by keeping $\mathrm{F} / \mathrm{H}$ at 0.3 . Also for the 'with axial and with initial stress' the pipe was pre-stressed before commencing the real buckling simulation. Figure 12 shows the comparison of normalised peak buckling load varying with normalised OOS for three different cases. Difference between the normalised peak loads increases significantly with higher normalised OOS. It is evident from the figure that peak load in the pipe is higher with axial resistance and highest with axial resistance and initial stress. For $\Delta / \mathrm{L}=0.5$ the value of dimensionless peak load for 'with axial and without initial stress' is 1.43 times higher than that for 'without axial' case due to the addition of axial springs along the length of the pipeline. Similarly, initial stress in the pipe increases the peak load further 1.11 times for the same $\Delta L$ value. Based on these results a comprehensive parametric study was carried out in the next section.

\section{RESULTS OF PARAMETRIC STUDY}

Many numerical analyses were carried out for a range of cases to establish a general relationship for the critical buckling load, $P_{c r}$. This load was found by analysis of the responses from $>200$ separate analyses using a range of pipe and pipe-soil parameters, including different $\Delta / L$ ratios. Pipe with three different sizes of $0.152 \mathrm{~m}\left(6^{\prime \prime}\right), 0.304 \mathrm{~m}\left(12^{\prime \prime}\right)$ and $0.912 \mathrm{~m} \mathrm{(36")}$ with $\mathrm{D} / \mathrm{t}$ ratio of 30, were considered. The results were plotted in nondimensionalised manner all cases. First a design chart was proposed based on a parametric study without any initial stress or an axial pipesoil spring. Then the individual effect of parameters such as ultimate soil resistance and $O O S$ were investigated through a systematic parametric study. Finally another design chart was proposed for the case with initial stress and axial pipe-soil spring.

\subsubsection{Without initial stress and axial spring}

In this step only lateral nonlinear springs were used along the length of the pipeline. No axial restraint was applied except for the fixed end boundary condition. The critical buckling load for various embedment ratios and for various ultimate soil resistances was plotted and the following nondimensionalised fit was developed: 


$$
\frac{P_{c r} \cdot \Delta^{2}}{E I}=0.75\left(\frac{\Delta}{L}\right)^{-0.667}\left(\frac{H \cdot \Delta^{3}}{E I}\right)^{0.667}\left(\frac{k_{y}}{H} \sqrt{\frac{8 E I}{E A}}\right)^{0.1}\left(\frac{\Delta}{\sqrt{8 E I / E A}}\right)^{-0.1}
$$

Figure 13 illustrates the comparison between the actual critical buckling load and the predicted critical buckling load. The proposed multivariate fit shows a good agreement with the FE results. The mean absolute error $\left|1-P_{\text {cr_predicted }} / P_{\text {cr_FEA }}\right|$ between equation (24) and the FEA result was 0.14 with standard deviation value of 0.033 . Whereas Maltby \& Calladine [7] solution gives an error of 1.01 with a standard deviation value of 0.059 . Therefore, predicted critical buckling load is in good agreement with the FEA results.

\subsubsection{Without initial stress and with axial spring}

In this step along with axial and lateral nonlinear springs, axial springs were also used along the length of the pipeline. Similar to the previous cases the critical buckling load for various embedment ratios and for various ultimate soil resistances was developed into a nondimensionalised fit:

$$
\frac{P_{c r} \cdot \Delta^{2}}{E I}=1.15\left(\frac{\Delta}{L}\right)^{-0.66}\left(\frac{H \cdot \Delta^{3}}{E I}\right)^{0.66}\left(\frac{k_{y}}{H} \sqrt{\frac{8 E I}{E A}}\right)^{0.1}\left(\frac{\Delta}{\sqrt{8 E I / E A}}\right)^{-0.1}\left(\frac{F}{H}\right)^{-0.17}\left(\frac{k_{x}}{F} \sqrt{\frac{8 E I}{E A}}\right)^{-0.12}
$$

This solution verifies the classical buckling solution and extends it with axial and lateral soil stiffness terms. Figure 14 illustrates the comparison between the calculated and predicted critical buckling load. The proposed multivariate fit shows good agreement with the FE results. The mean absolute error $\mid 1$ - $P_{\text {cr_predicted }} / P_{\text {cr_FEA }} \mid$ between equation (25) and FEA result was found out to be 0.63 with a standard deviation value of 0.058 , which is again an improvement on Maltby \& Calladine [7], for which the mean error was 2.67 and value of standard deviation was 0.087 .

However, the solution does not include the initial stress in the pipe due to its shape and the axial component of the soil resistance. The following section adds these aspects.

\subsubsection{With initial stress and axial springs}

In the field due to the pipe lay process and any uneven seabed topography, the pipe gains an OOS and hence the pipe is pre-stressed, prior to the addition of axial stresses. As discussed earlier, the pipe was considered to be initially straight and then a lateral displacement was given to the pipe to derive the required OOS. Therefore, the pipe was pre-stressed before commencing the real buckling. At this stage the springs along the length of the pipe were deactivated and did not impose 
any resistance to the lateral displacement to achieve the deformed shape. Thereafter, all the springs were activated and buckling analyses was carried out, via displacement control simulation. Similar to the previous cases, the ratio $\Delta / L$ was varied between 0.01 to 0.05 to cover a wide range of OOSs.

Finally, the effect of all soil parameters and the as-laid geometry on the critical lateral buckling load of a pre-stressed pipeline is given by the nondimensionalised form as

$$
\frac{P_{c r .} \Delta^{2}}{E I}=1.35\left(\frac{\Delta}{L}\right)^{-0.66}\left(\frac{\mathrm{H} . \Delta^{3}}{E I}\right)^{0.66}\left(\frac{\mathrm{k}_{y}}{H} \sqrt{\frac{8 E I}{E A}}\right)^{0.1}\left(\frac{\Delta}{\sqrt{8 E I / E A}}\right)^{-0.1}\left(\frac{\mathrm{F}}{H}\right)^{-0.26}\left(\frac{\mathrm{k}_{x}}{F} \sqrt{\frac{8 E I}{E A}}\right)^{-0.18}
$$

Figure 15 shows the comparison between the actual and the predicted normalised critical buckling load of pre-stressed pipeline on a soft seabed. The mean absolute error $\mid 1-P_{\text {cr_predicted }}$ $/ P_{\text {cr_FeA }}$ between equation (26) and FEA result was 0.14 with a standard deviation value of 0.068 , which is an improvement on the Maltby \& Calladine [7] solution, for which the mean error was 0.58 and with a standard deviation value of 0.084 . The multivariate fit shows good agreement with the actual FE results. The increase in peak load due to initial stress in the pipe was also observed by the others [23, 32]. Therefore, the results can be used by the designers to predict the buckling load of an imperfect pipe laid on a soft seabed.

\section{CONCLUSION}

The paper reports an investigation of the lateral buckling problem of on-bottom pipeline subjected to axial compressive loading. A detailed prediction method based on a multi-variate fit to the relevant dimensionless groups was developed to predict critical buckling load.

The seabed was idealised with horizontal, axial elastic, perfectly plastic, springs to idealise the load-displacement behaviour of the soil and the pipe was modelled with pipe elements. Buckling was performed by a displacement controlled finite element method with the modified RIKS algorithm that is available in the commercial software ABAQUS. In the first step the classical theories were verified with the numerical tool and a simple multivariate fit was proposed by carrying out parametric study. Then in the next steps actual analysis was carried out by incorporating the axial springs and the initial stress into the numerical model. The results have been synthesised in a generic non-dimensionalised design chart to estimate the buckling load, valid for the range of inputs covered by the parametric study. 


\section{Acknowledgements}

The research presented here forms part of the activities of the Centre for Offshore Foundation Systems (COFS), currently supported as a node of the Australian Research Council Centre of

Excellence for Geotechnical Science and Engineering (grant CE110001009) and through the Fugro Chair in Geotechnics, the Lloyd's Register Foundation Chair and Centre of Excellence in Offshore Foundations and the Shell EMI Chair in Offshore Engineering. 


\section{References:}

[1] Carr, M., Sinclair, F., \& Bruton, D. (2006). Pipeline Walking - Understanding the filed layout challenges, and analytical solutions developed for the SAFEBUCK JIP. Proc. of Offshore Technology Conference, Houston, USA, OTC 17945.

[2] Allan, T. (1968). One-way buckling of compressed strip under lateral loading. J. Mech. Engng Sci. 10, 175.

[3] Hobbs, R. E. (1981). Pipeline buckling caused by axial loads. J. Construct. Steel Res. 1(2), $2-10$.

[4] Hobbs, R. E. (1984). In-service buckling of heated pipelines. J. Transport Eng., 110(2), 175189.

[5] Kerr, A. D. (1974). On the stability of the railroad track in the vertical plane. Rail Int. 5: 132142.

[6] Kerr, A. D. (1978). Analysis of thermal track buckling in the lateral plane. Acta Mech. 30 (1-2): 17-50. https://doi.org/10.1007/BF01177436.

[7] Maltby, T. S., and Calladine, C. R. (1995). An investigation into upheaval buckling of buried pipelines-II. Theory and analysis of experimental observations. Int. J. Mech. Sci. 37(9), 965-983.

[8] Croll, J. G. A. (1997). A simplified model of upheaval thermal buckling of seabed pipelines. Thin-Walled Structures. 29(1- 4), 59-78.

[9] Taylor, N., and Tran, V. (1996). Experimental and theoretical studies in subsea pipeline buckling. Marine Structures. Vol. 9, 211-257.

[10] Hetényi, M. (1946). Beams on elastic foundation. Univ. of Michigan Press, Ann Arbor, MI.

[11] Collberg, L., J. Mork, K., Levold, E., \& Vitali, L. (2005). HotPipe JIP: Design Guidelines for HP/HT Pipelines. 683-690. 10.1115/OMAE2005-67523.

[12] Bruton, D., \& Carr, M. (2011). Overview of the SAFEBUCK JIP. 10.4043/21671-MS.

[13] Massey, B.S. (1971). Units, Dimensional Analysis and Physical Similarity. University College London, Van Nostrans Reinhold Company, London.

[14] Tvergaard, V., and Needleman, A. (1980). On the localization of buckling patterns. J. Appl. Mech, Vol. 47, 613-620.

[15] Dassault Systèmes (2007) Abaqus analysis users' manual, Simula Corp, Providence, RI, USA.

[16] Perinet, D., and Simon, J. (2011). Lateral buckling and pipeline walking mitigation in deep water. Proc., of Offshore Technology Conference, Houston, USA, OTC-21803-MS.

[17] Guha, I., Randolph, M. F., and White, D. J . (2016). Evaluation of elastic stiffness parameters for pipeline-soil interaction. Accepted, J. Geotechnical and Geoenvironmental. Eng.

[18] Randolph, M. F. and White, D. J. (2008).Offshore Foundation Design - A Moving Target. Proc., of BGA International Conference on Foundations, Dundee, HIS BRE Press, London, 27-59. 
[19] Merifield, R. S., White, D. J., and Randolph, M. F. (2008). The ultimate undrained resistance of partially embedded pipelines. Géotechnique, 58(6), 461-470.

[20] White, D. J., and Randolph, M. (2007). Seabed Characterisation And Models For Pipelinesoil Interaction. Proceedings of the International Offshore and Polar Engineering Conference. 17.

[21] Riks, E. (1979). An incremental approach to the solution of snapping and buckling problems. Int. J. Solids \& Structure, Vol. 15, 524-551.

[22] Sriskandarajah, T., Dong, S., S. Sribalachandran, S., and Wilkins, R. (1999). Effect of initial imperfection on the lateral buckling of Subsea pipelines. Proc., of 9th International Offshore and Polar Engineering Conference, Brest, France, 168-175.

[23] Zhou, T., Tian, Y., White, D. J., and Cassidy, M. J. (2019). Finite element modelling of offshore pipeline lateral buckling. J. Pipeline Syst. Eng. Pract., 10 (4): DOI: 10.1061/(ASCE)PS.1949-1204.0000396

[24] Wang, Z., Huachen, Z., Liu, H., and Bu, Y. (2015). Static and dynamic analysis on upheaval buckling of unburied subsea pipelines. Ocean Engineering, 104, 249-256,

[25] Torselleti, E., Vitali, L., and Levold, E. (1999). Hotpipe Project: Snaking of submarine pipelines resting on flat sea bottom using finite element method. Proc., of 9th International Offshore and Polar Engineering Conference, Brest, France, 34-45.

[26] Maschner, E. A., and Wang, N. Y. (2008). Risk design for stable 'thin-walled' pipelines subjected to global buckling and excessive bending from seabed and pipelay induced outof-straightness. Proc., of $27^{\text {th }}$ International Conference on Offshore Mechanics and Arctic Engineering, ASME, Portugal, OMAE2008-57067.

[27] Peek, R., \& Yun, H. (2007). Flotation to triggred lateral buckles in pipelines on a flat seabed. J. Eng. Mech. 133(4), 442-451.

[28] Odina, L., and Tan, R. (2009). Seismic fault displacement of buried pipelines using continuum finite element methods. Proc., of $28^{\text {th }}$ International Conference on Ocean, Offshore and Arctic Engineering, ASME, Hawaii, USA, OMAE2009-79739.

[29] Chee, J., Walker, A., \& White, D. (2019). Effects of variability in lateral pipe-soil interaction and pipe initial out-of-straightness on controlled lateral buckling of pre-deformed pipeline. Ocean Engineering, 182, 283-304. DOI: 10.1016/j.oceaneng.2019.04.034

[30] Chee, J., Walker, A., \& White, D. (2018). Controlling lateral buckling of subsea pipeline with sinusoidal shape pre-deformation. Ocean Engineering, 151, 170-190. DOI: 10.1016/j.oceaneng.2018.01.024

[31] Sollund, H., and Vedeld, K. (2014). A finite element solver for modal analysis of multi-span offshore pipelines. Dept. of Math, University of Oslo, Research Report in Mechanics, No.1, ISSN 0801-9940.

[32] Miles, D. J. (1998). Lateral Thermal Buckling of Pipelines, Ph.D. dissertation, University of Cambridge, Cambridge, UK. 
Tables:

Table 1: Summary table of estimation of critical load of buckling of submarine pipelines:

\begin{tabular}{|c|c|c|c|}
\hline & Critical buckling load & Model description & Reference \\
\hline 1 & $\begin{array}{l}\text { Vertical mode -thin strip on flat table } \\
\qquad P=3.95 \sqrt{\frac{w E I}{\Delta}} \\
\text { Where } w=\text { distributed load per unit length, } \\
\text { EI }=\text { bending rigidity and } \Delta=\text { initial } \\
\text { imperfection }\end{array}$ & Upheaval buckling of thin strip under axial compressive loading with & Allan (1968) \\
\hline $2 a$. & $\begin{array}{l}\text { Vertical mode -straight pipe on flat } \\
\text { seabed } \\
P=80.8 E I / L^{2} \\
\text { Where } E I=\text { bending rigidity and } L= \\
\text { length of the buckle and given by }\end{array}$ & & Hobbs (1981, 1984) \\
\hline
\end{tabular}




\begin{tabular}{|c|c|c|c|}
\hline $2 b$. & $\begin{array}{l}L=\left(\frac{1.6856 \times 10^{6}(E I)^{3}}{w^{2} A E}\right)^{0.125} \\
\text { Where } A=\text { area of the pipe, } w=\text { weight of } \\
\text { the pipe per unit length } \\
\text { Lateral mode -straight pipe on flat } \\
\text { seabed } \\
P=4 \pi^{2} E I / L^{2} \\
\text { Where } E I=\text { bending rigidity and } L= \\
\text { length of the buckle and given by } \\
\qquad L=\left(\frac{9.0474 \times 10^{5}(E I)^{3}}{(\mu .125}\right) \\
\text { Where } \mu=\text { coefficient of friction, } A=\text { area } \\
\text { of the pipe, } w=\text { weight of the pipe per unit } \\
\text { length }\end{array}$ & $\begin{array}{l}\text { Both upheaval and lateral critical buckling loads are derived and } \\
\text { expressed as a function of length of the buckle. It was assumed that the } \\
\text { bending moment and slope at the lift-off point is zero. For the lateral } \\
\text { mode the lateral friction force is fully mobilised and the zero slope } \\
\text { condition at the end is replaced by the shear force condition at the same } \\
\text { place. }\end{array}$ & Hobbs $(1981,1984)$ \\
\hline $3 a$. & $\begin{array}{l}\text { Vertical mode-straight pipe on flat } \\
\text { seabed }\end{array}$ & & \\
\hline
\end{tabular}




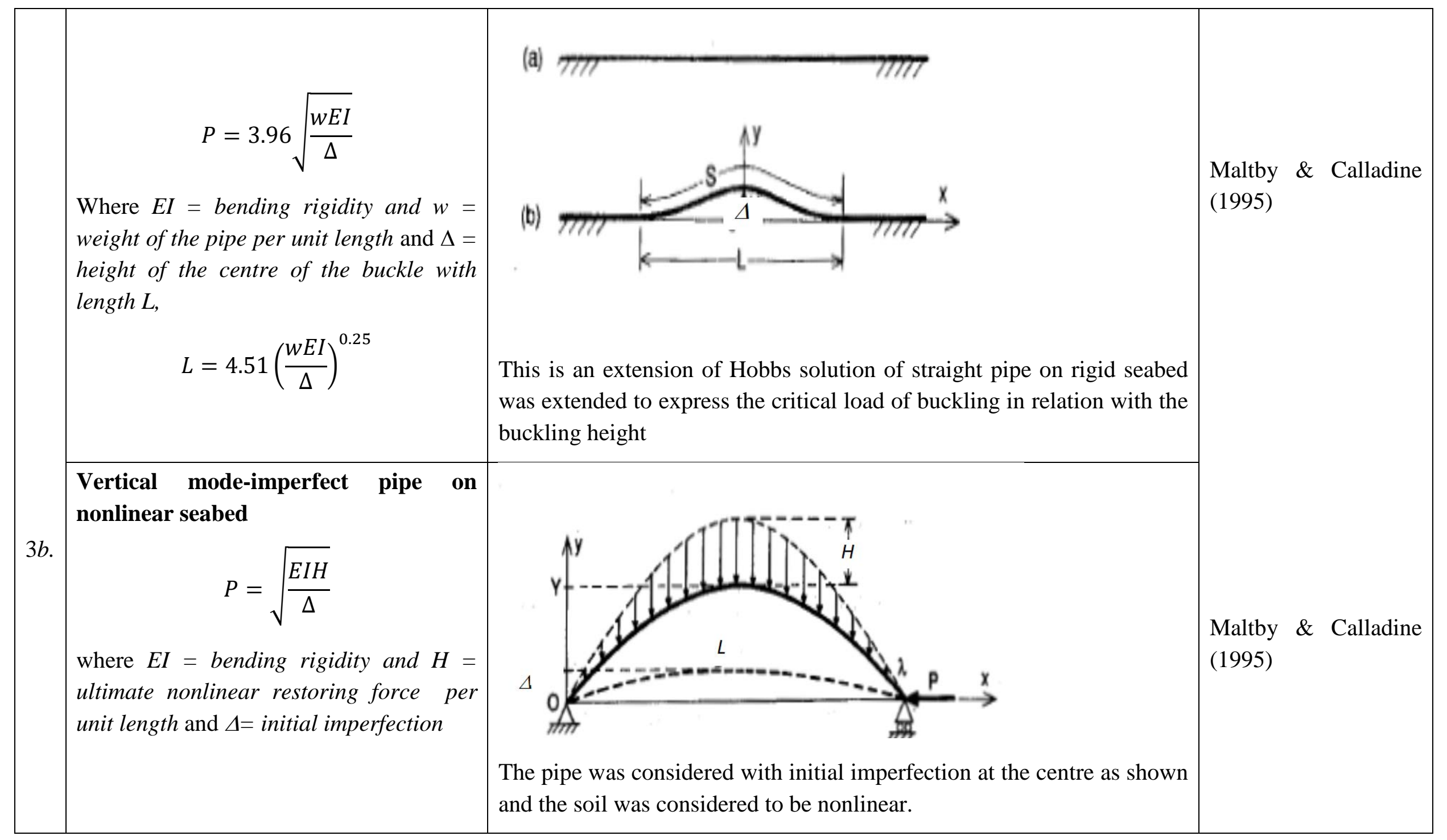




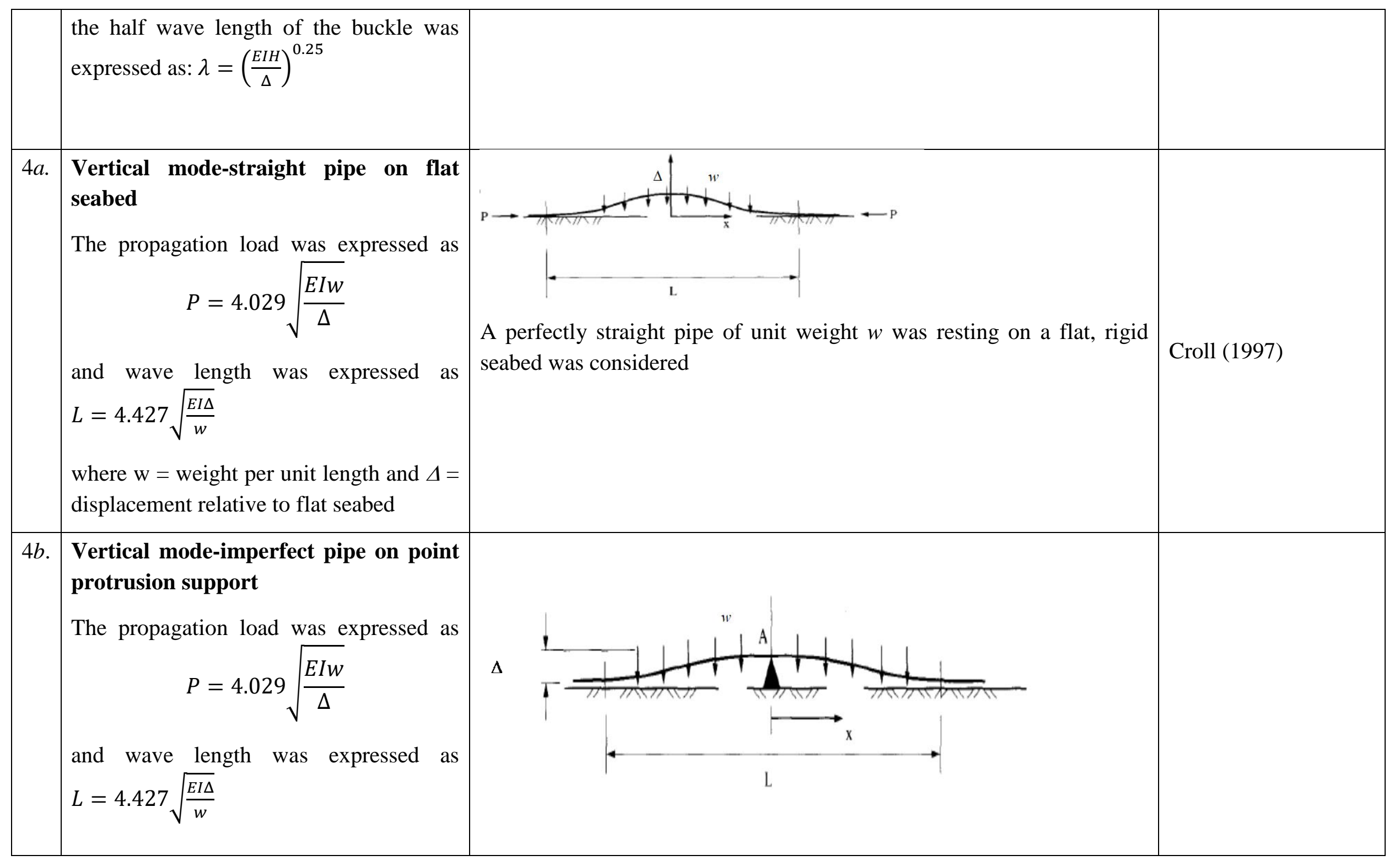




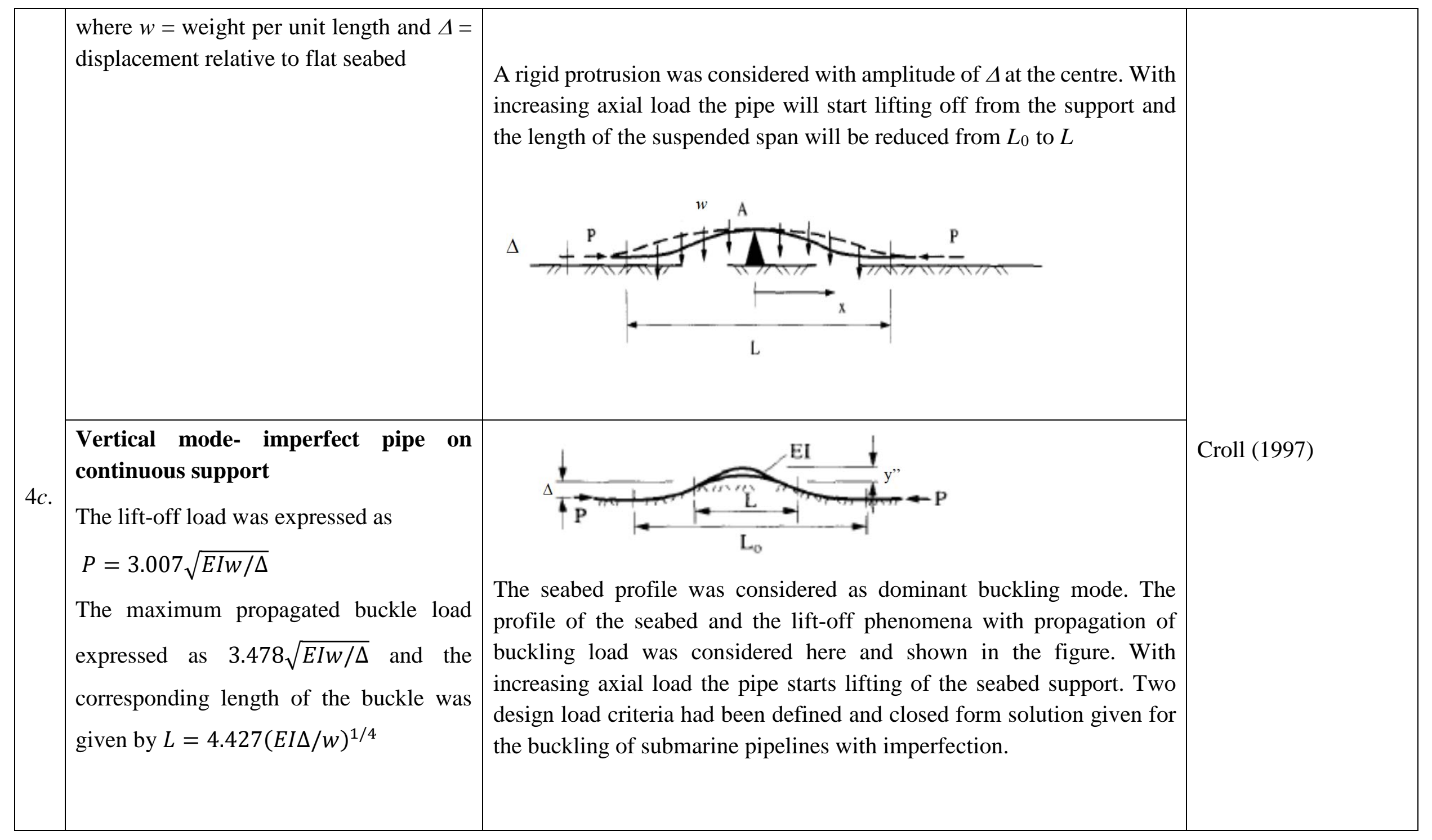




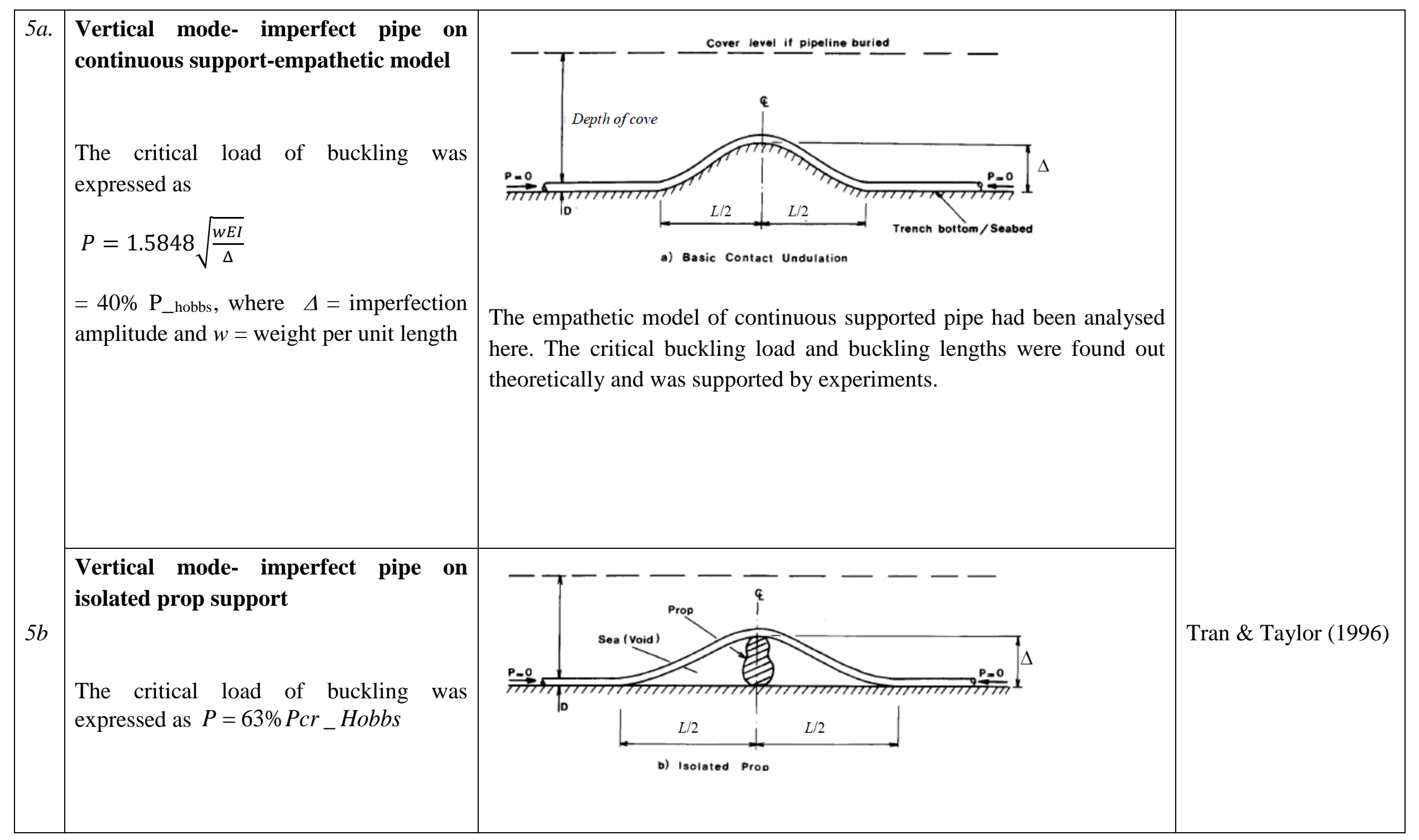




\begin{tabular}{|c|c|c|c|}
\hline $5 c$ & $\begin{array}{l}\text { Vertical mode- imperfect pipe on } \\
\text { isolated filled-prop support } \\
\text { The critical load of buckling was } \\
\text { expressed as } P=25.2 \% \mathrm{PCr}_{-} \mathrm{Hobbs}\end{array}$ & $\left.\right|_{\text {c) Intilled Prop }} ^{L-1}$ & \\
\hline 6 & $\begin{array}{l}\text { Straight bar under simultaneous axial } \\
\text { and transverse loading } \\
P=2 \sqrt{k E I} \text { where } k=\text { modulus of the } \\
\text { foundation or the stiffness in case of soil. }\end{array}$ & $\begin{array}{l}\text { In this model a bar was considered to be straight and on elastic foundation } \\
\text { under axial compression. }\end{array}$ & Hetényi, 1946 \\
\hline $7 a$. & $\begin{array}{l}\begin{array}{l}\text { Lateral mode-straight pipe on flat } \\
\text { seabed }\end{array} \\
\qquad P=3.86\left(\frac{w \mu E I}{D}\right) \\
\text { where } w=\text { submerged pipe weight, } \mu= \\
\text { coefficient of friction, } D=\text { diameter of } \\
\text { pipe }\end{array}$ & Modified Hobbs solution for infinite mode of buckling & SAFEBUCK II 2008 \\
\hline
\end{tabular}




\begin{tabular}{|c|l|l|l|}
\hline $7 b$. & $\begin{array}{l}\text { Vertical mode-with imperfection / OOS } \\
\text { on flat seabed }\end{array}$ & Modified Hobbs solution \\
$\qquad P=3.86 \sqrt{\frac{w E I}{\Delta}}$ & & SAFEBUCK II 2008 \\
where $\Delta=$ vertical trigger height & & \\
\hline
\end{tabular}


Table 2: Summary of input output parameters:

\begin{tabular}{lll}
\hline Input parameters & Symbols & Units \\
\hline Out-of-straightness & $\Delta$ & $\mathrm{m}$ \\
Nominal length of the OOS & $L$ & $\mathrm{~m}$ \\
Ultimate lateral resistance & $H$ & $\mathrm{kN} / \mathrm{m}$ \\
Ultimate axial resistance & $F$ & $\mathrm{kN} / \mathrm{m}$ \\
Lateral soil stiffness & $k_{y}$ & $\mathrm{kN} / \mathrm{m}^{2}$ \\
Axial soil stiffness & $k_{x}$ & $\mathrm{kN} / \mathrm{m}^{2}$ \\
Pipeline bending rigidity & $E I$ & $\mathrm{kN} \mathrm{m}{ }^{2}$ \\
Pipeline cross-sectional stiffness & $E A$ & $\mathrm{kN}$ \\
\hline Output parameters & Symbols & $\mathrm{Units}$ \\
\hline Critical buckling load & $P_{c r}$ & $\mathrm{kN}$ \\
\hline
\end{tabular}


Table 3: Range of Input Parameters Considered

\begin{tabular}{lll}
\hline & Quantity & Range \\
\hline Raw parameters & Diameter $D$ & $0.152 \mathrm{~m}, 0.304 \mathrm{~m}$ and $0.912 \mathrm{~m}$ \\
& Out-of-straightness $\Delta$ & $0.5-10 \mathrm{~m}$ \\
& Nominal length of the $O O S, L$ & $50-200 \mathrm{~m}$ \\
& Lateral soil resistance $H$ & $0.002-30 \mathrm{kN} / \mathrm{m}$ \\
& Axial soil resistance $F$ & $0.0008-3.5 \mathrm{kN} / \mathrm{m}$ \\
& Lateral soil stiffness $k_{y}$ & $0.054-288.27 \mathrm{kN} / \mathrm{m}^{2}$ \\
& Axial soil stiffness $k_{x}$ & $0.043-228.78 \mathrm{kN} / \mathrm{m}^{2}$ \\
Bending rigidity $E I$ & $1.24-1.62 \times 10^{6} \mathrm{kN} \mathrm{m}{ }^{2}$ \\
Axial stiffness EA & 0.46 to $16.6 \mathrm{kN}$ \\
$\Delta / L$ & $0.01-0.05$ \\
H. $\Delta^{3} / E I$ & $2.95 \times 10^{-7}-0.005$ \\
$F / H$ & $0.06-2.86$ \\
$k_{y} / H \cdot \Delta \sqrt{ } 8 E I / E A$ & $1.22-70.7$ \\
$k_{x} / F \cdot \Delta \sqrt{ } 8 E I / E A$ & $2.94-181$ \\
$\Delta / \sqrt{ } 8 E I / E A$ & $0.56-67.9$ \\
\hline
\end{tabular}

Table 4 : Values of pipe and soil calculated input parameters

\begin{tabular}{lll}
\hline & Quantity & Value \\
\hline Raw soil \& pipe & Thickness to diameter ratio $t / D$ & 0.033 \\
parameters & Embedment ratio $w / D$ & 0.5 \\
& $k=s_{u} / z$ & $5 \mathrm{kN} / \mathrm{m} 3$ \\
$G / s_{u}$ & 50 \\
& $m=G / z$ & $250 \mathrm{kN} / \mathrm{m} 3$ \\
\hline
\end{tabular}


Figure 1: Nonlinear springs considered for the axial and lateral directions...................... 32

Figure 2: Idealization of pipeline buckling model ....................................................... 32

Figure 3: Types of beam elements ( 2-node linear element used here) .............................. 33

Figure 4: Axial load displacement response at the central node of a buckle for a 6 " pipe with various out-of-straightness ................................................................ 33

Figure 5: Effect of out of straightness on peak buckling load ....................................... 34

Figure 6: Development of lateral displacement at buckle crown as axial load increases for

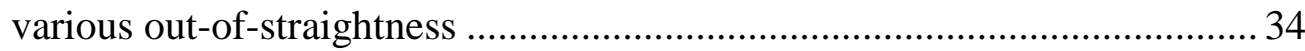

Figure 7: Mobilised lateral soil resistance at peak load along the length of the pipeline .. 35

Figure 8: Comparison between initial and displaced shapes at the peak loads for various out-of-straightness 35

Figure 9: Lateral offset values corresponding to peak load for various OOS .................... 36

Figure 10: Effect of lateral limiting frictional resistance on peak load.............................. 36

Figure 11: Effect of lateral elastic slip on peak load ..................................................... 37

Figure 12: Multivariate fit to computed critical buckling load without axial spring ......... 38

Figure 13: Multivariate fit to computed critical buckling load with axial spring ............... 38

Figure 14: Multivariate fit to computed critical buckling load with axial spring and initial stress 39 
Figures:

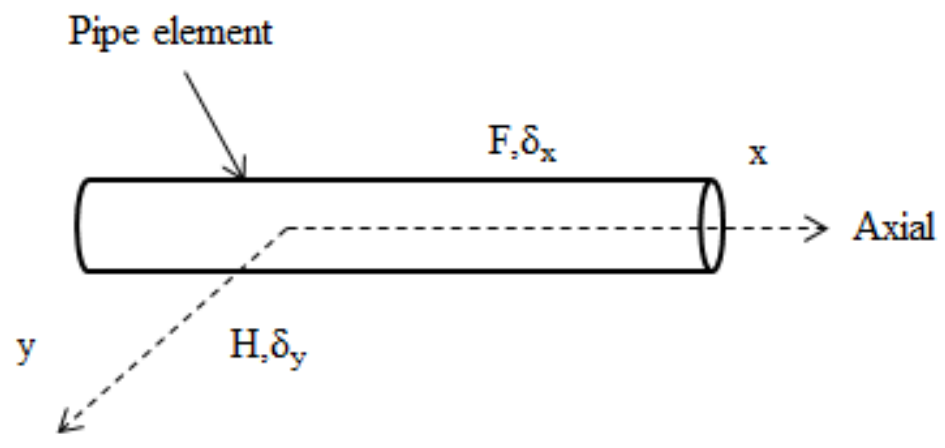

\section{Lateral}

Figure 1: Nonlinear springs considered for the axial and lateral directions

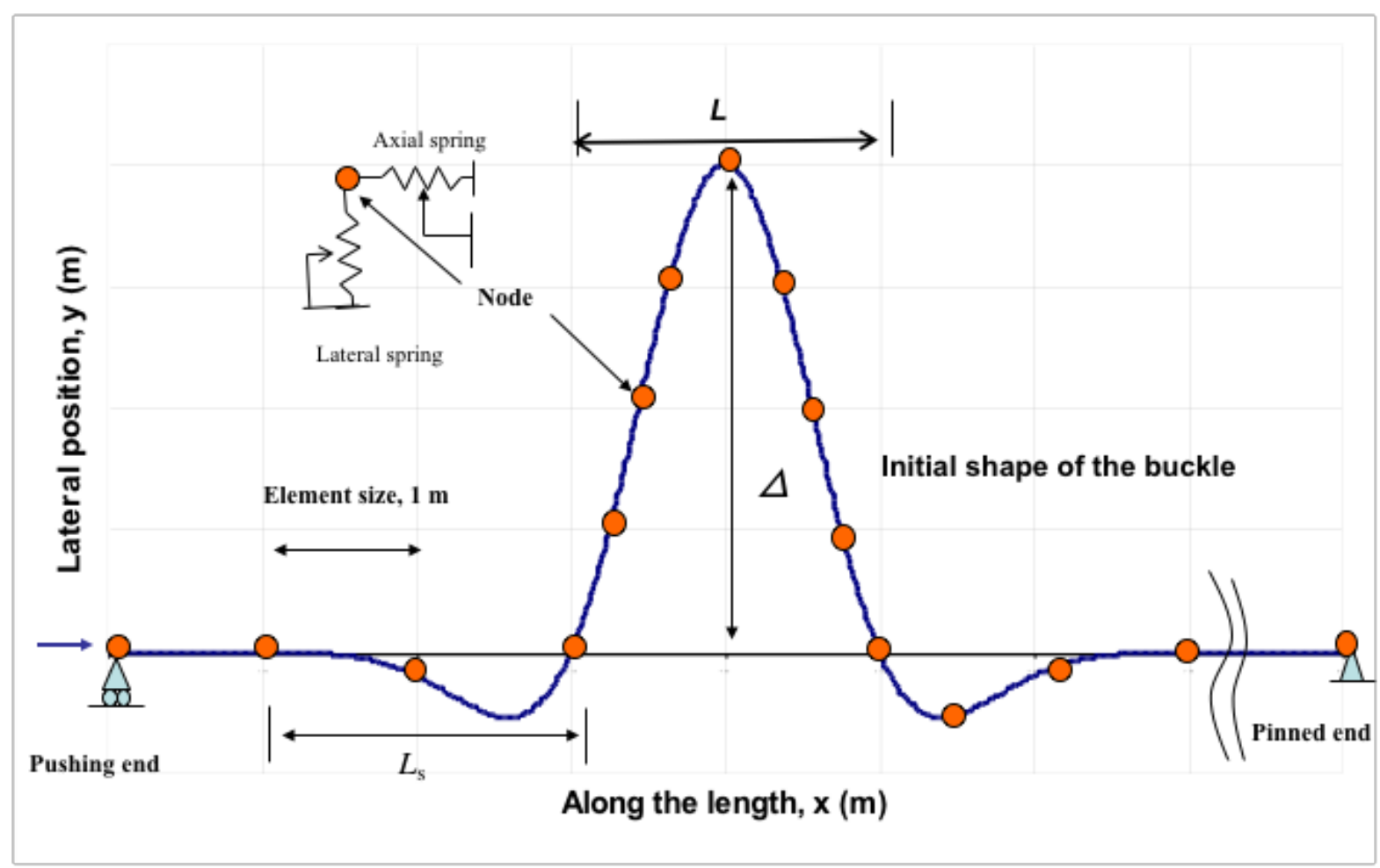

Figure 2: Idealization of pipeline buckling model 


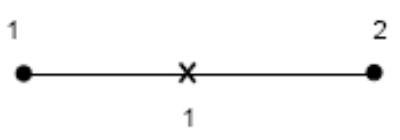

2-node element

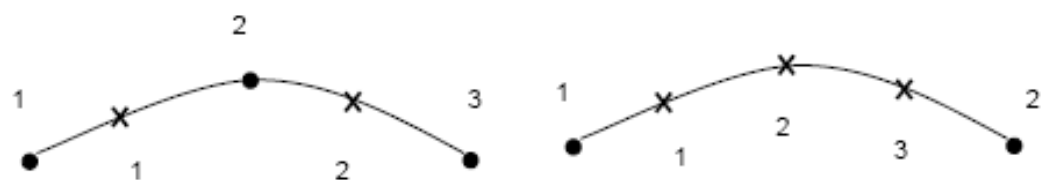

3-node quadratic element

Figure 3: Types of beam elements ( 2-node linear element used here)

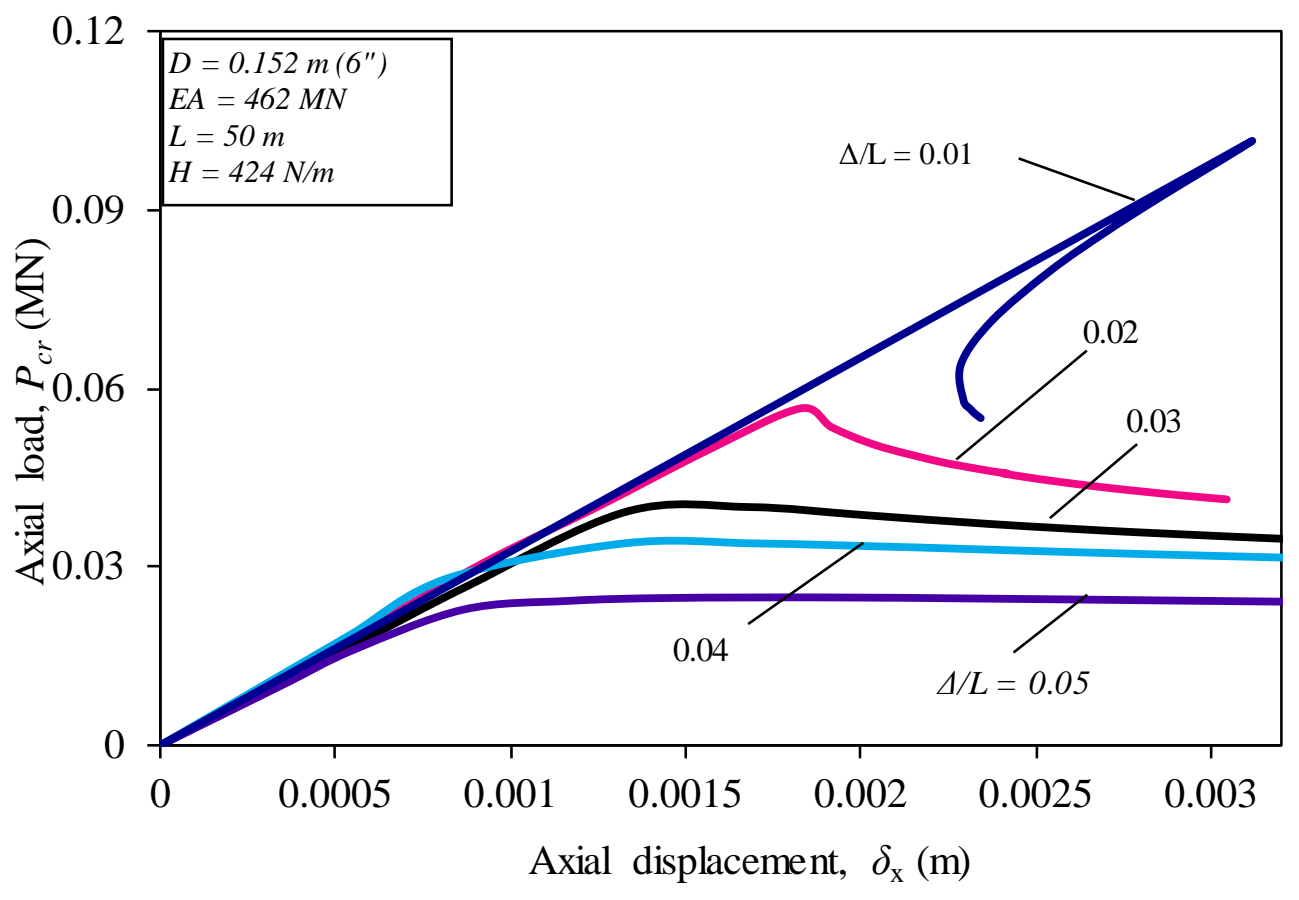

Figure 4: Axial load displacement response at the central node of a buckle for a 6" pipe with various out-ofstraightness 


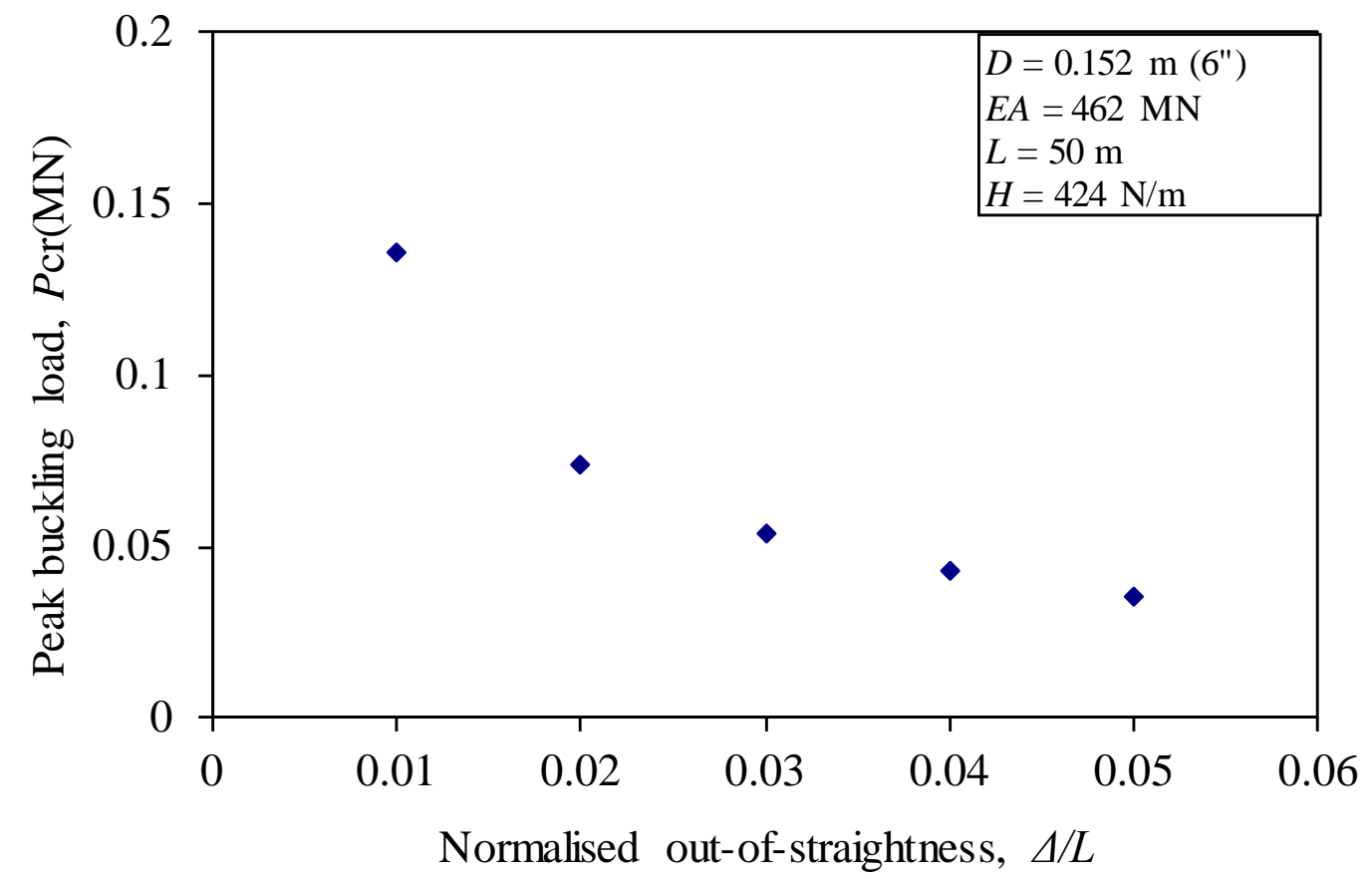

Figure 5: Effect of out of straightness on peak buckling load

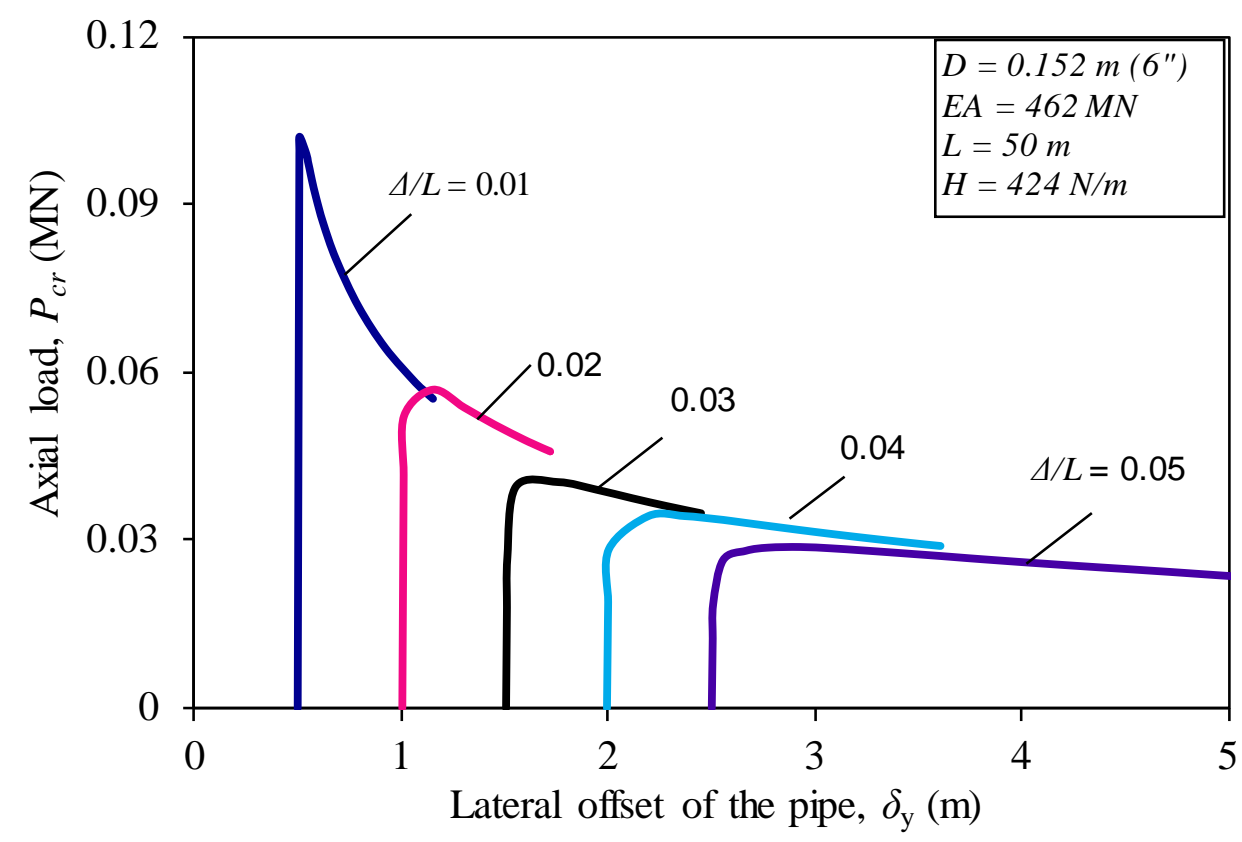

Figure 6: Development of lateral displacement at buckle crown as axial load increases for various out-ofstraightness 


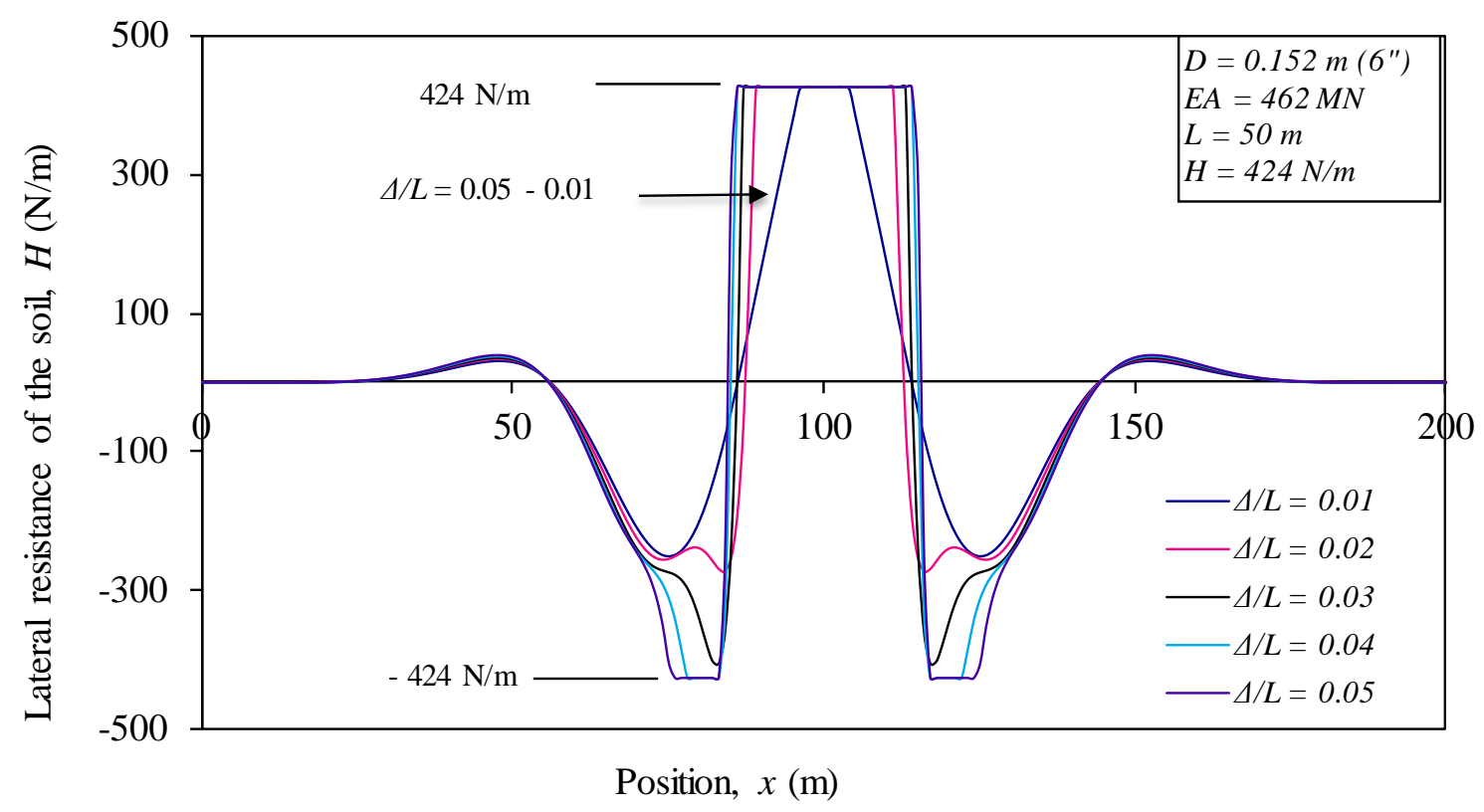

Figure 7: Mobilised lateral soil resistance at peak load along the length of the pipeline

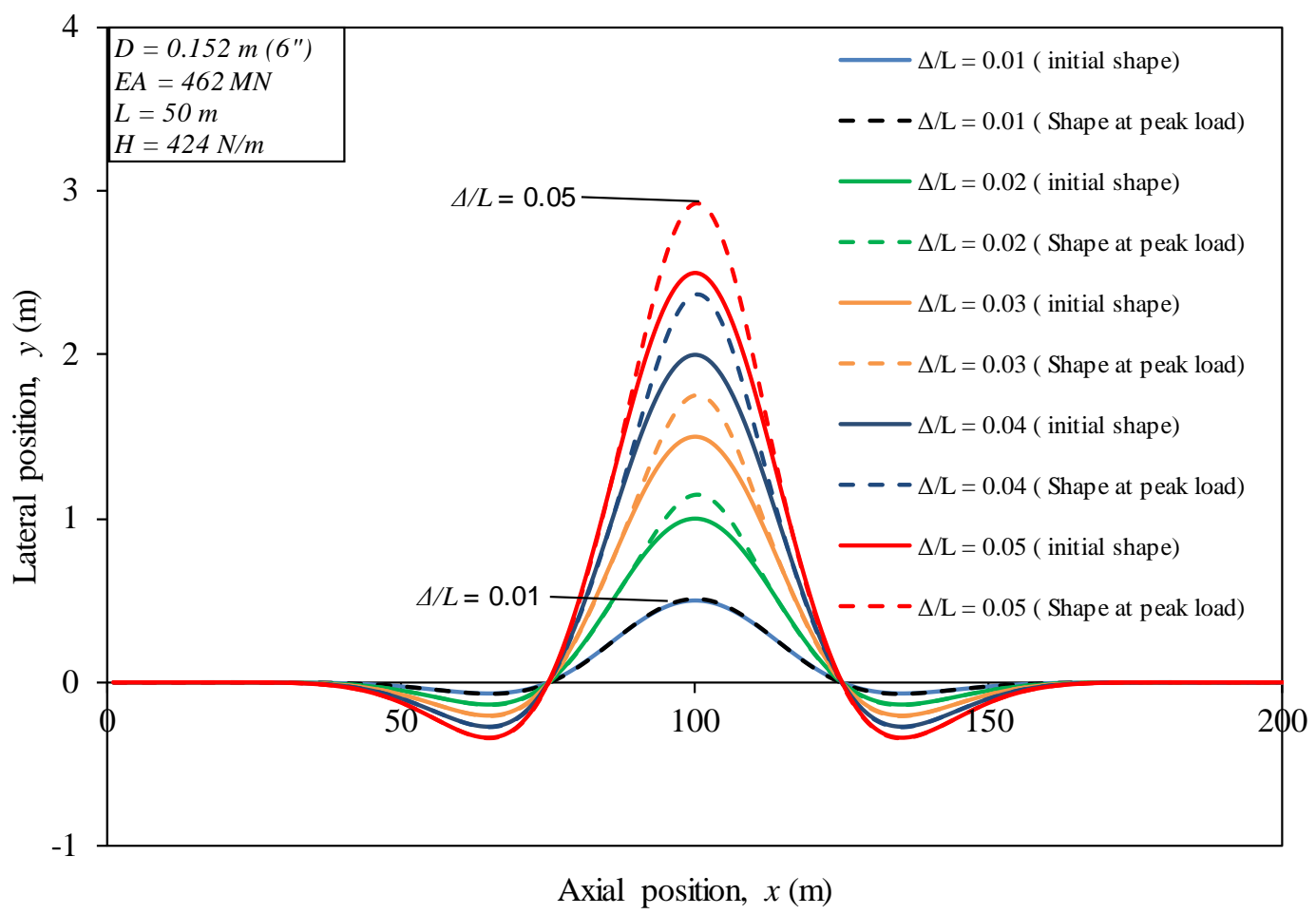

Figure 8: Comparison between initial and displaced shapes at the peak loads for various out-of-straightness 


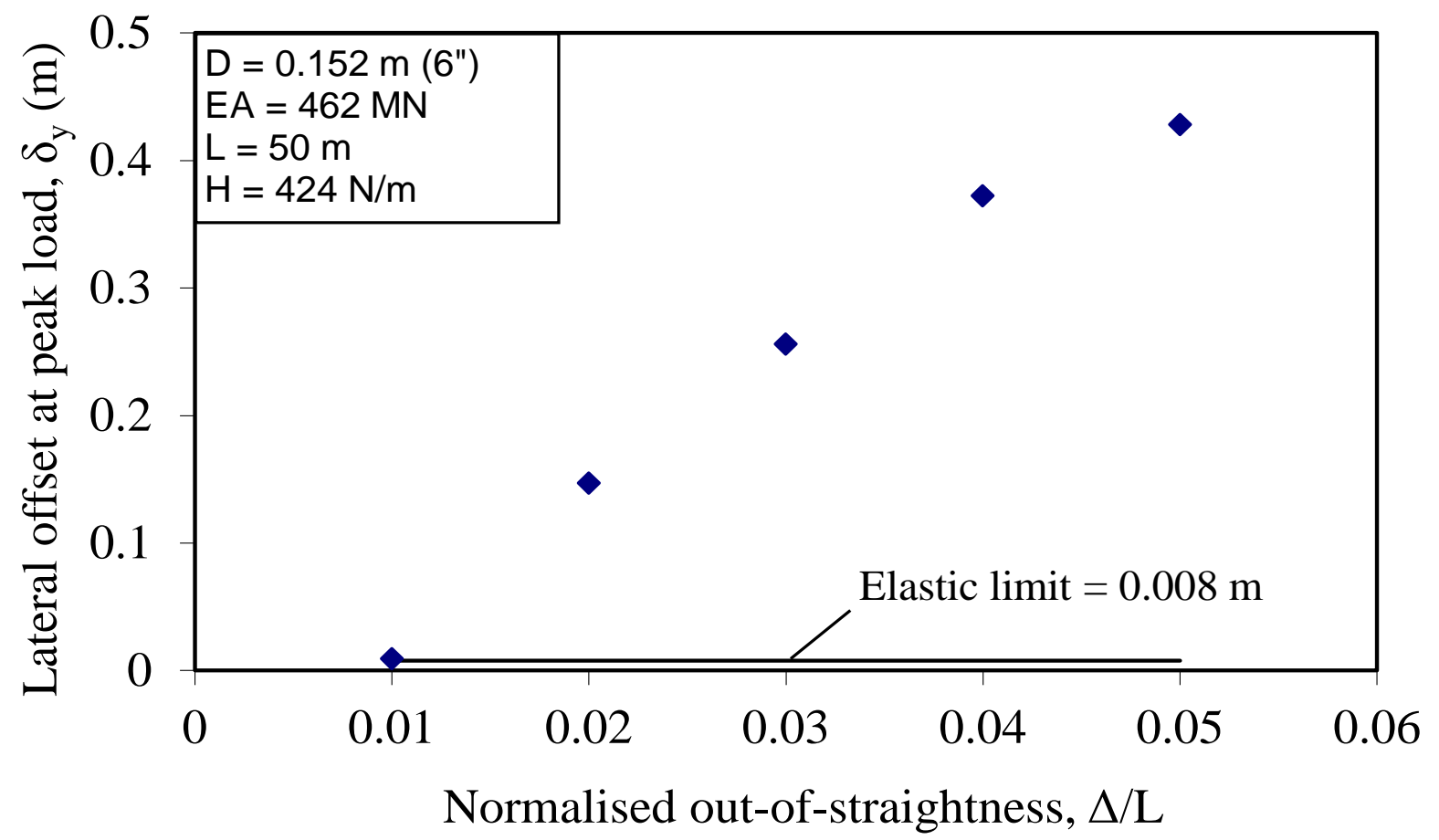

Figure 9: Lateral offset values corresponding to peak load for various OOS

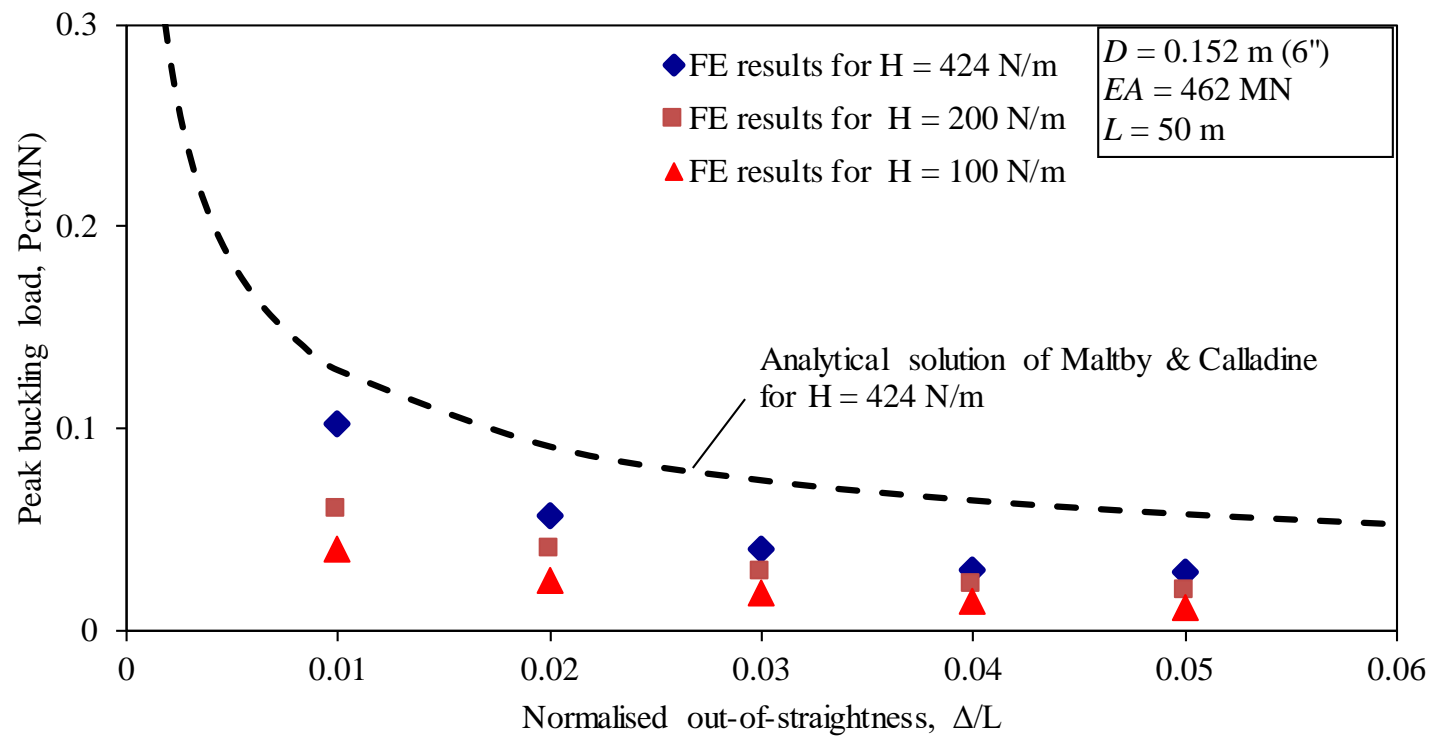

Figure 10: Effect of lateral limiting frictional resistance on peak load 


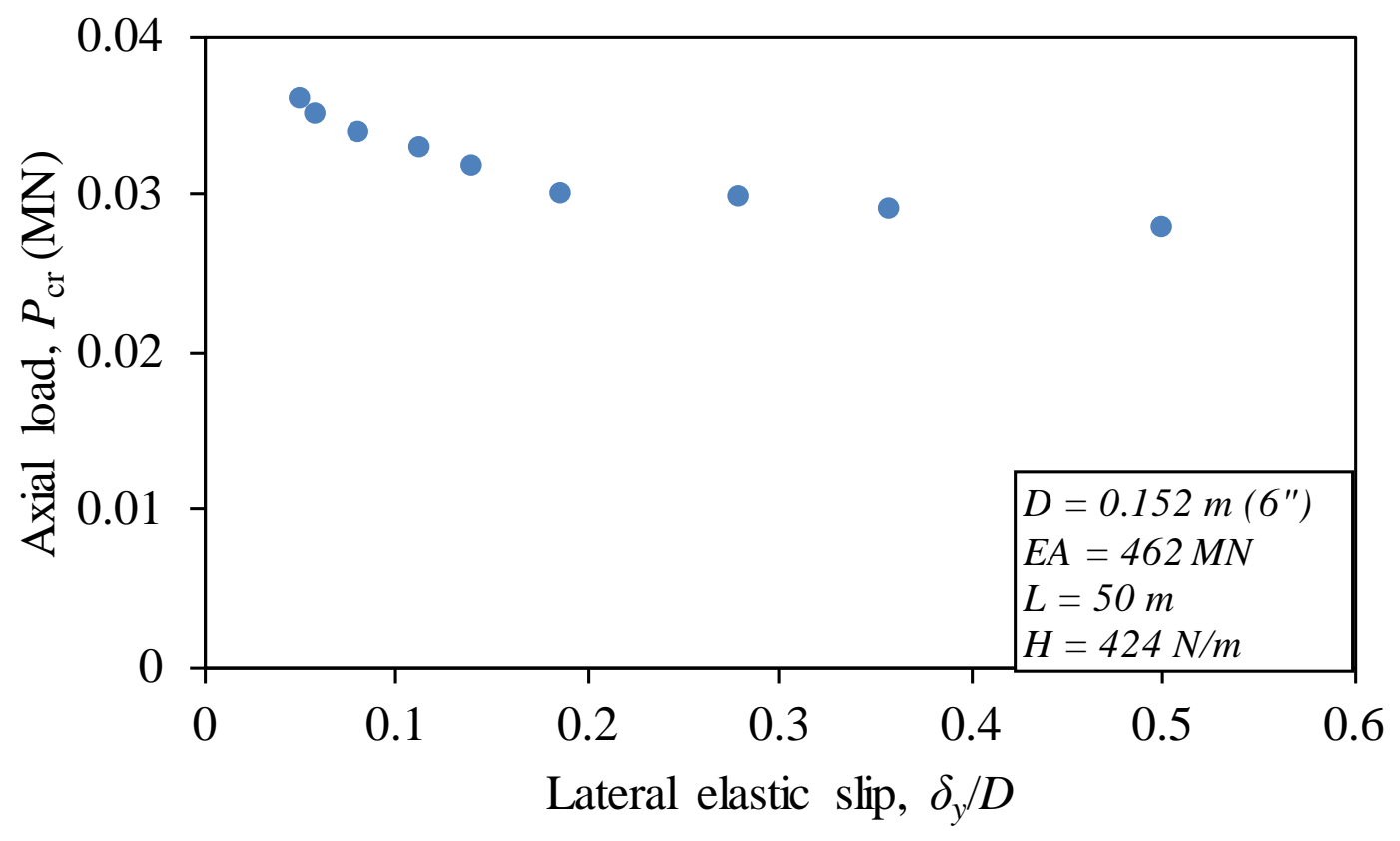

Figure 11: Effect of lateral elastic slip on peak load

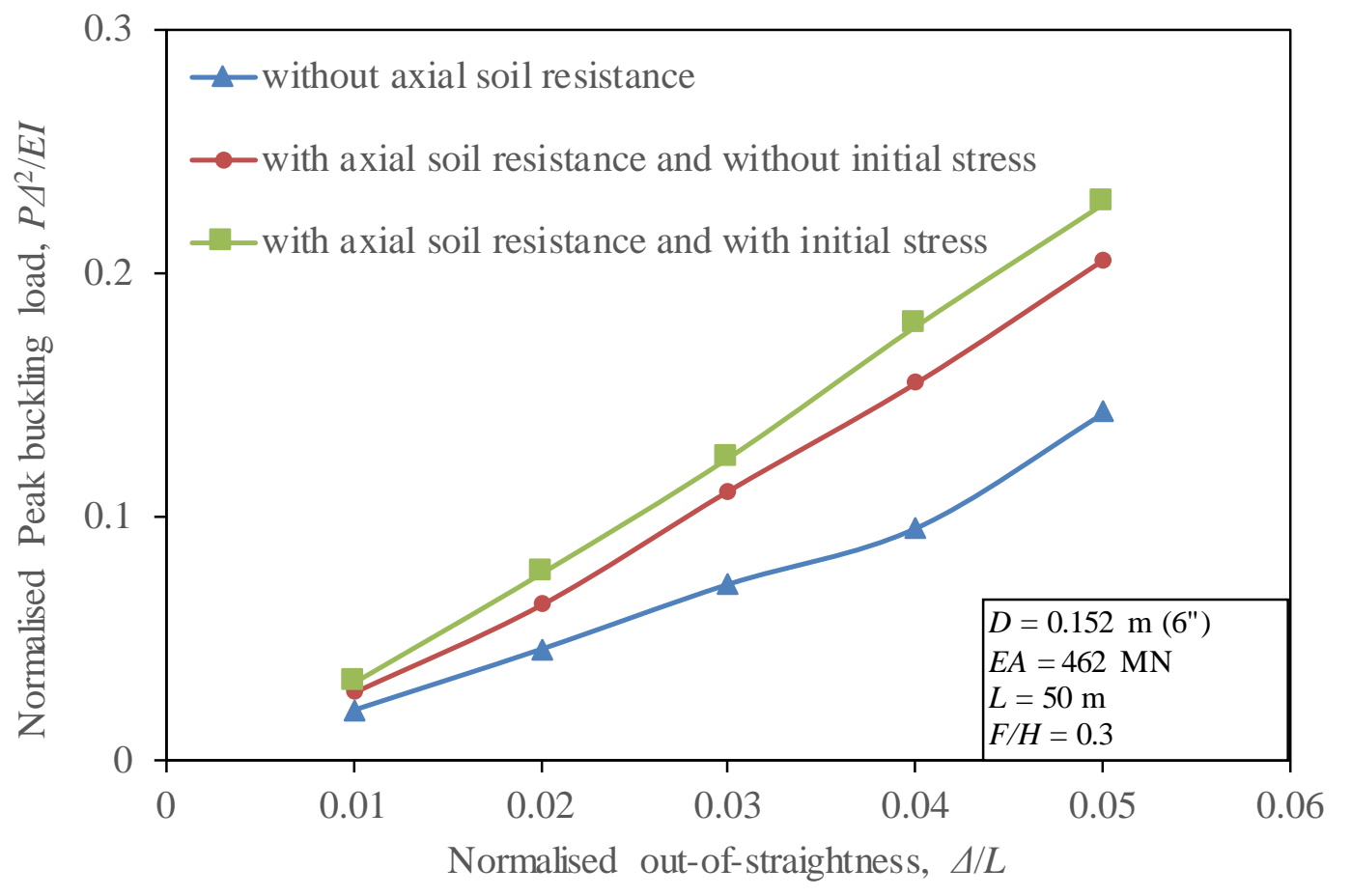

Figure 12: Comparison of normalised peak buckling loads for three cases 


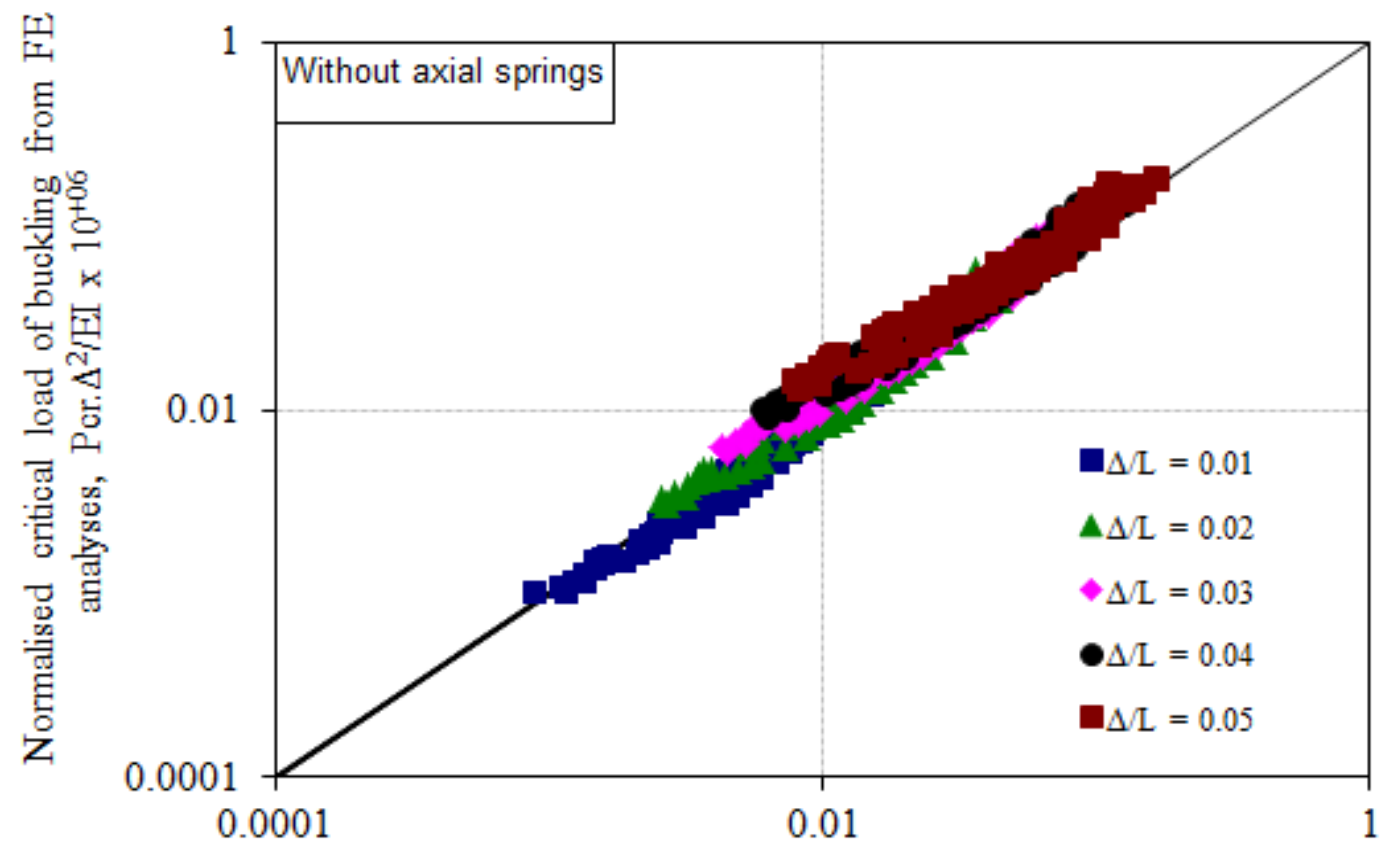

Normalised predicted critical load of buckling, Pcr. $\Delta^{2} /$ EI x $10^{+06}$

Figure 13: Multivariate fit to computed critical buckling load without axial spring

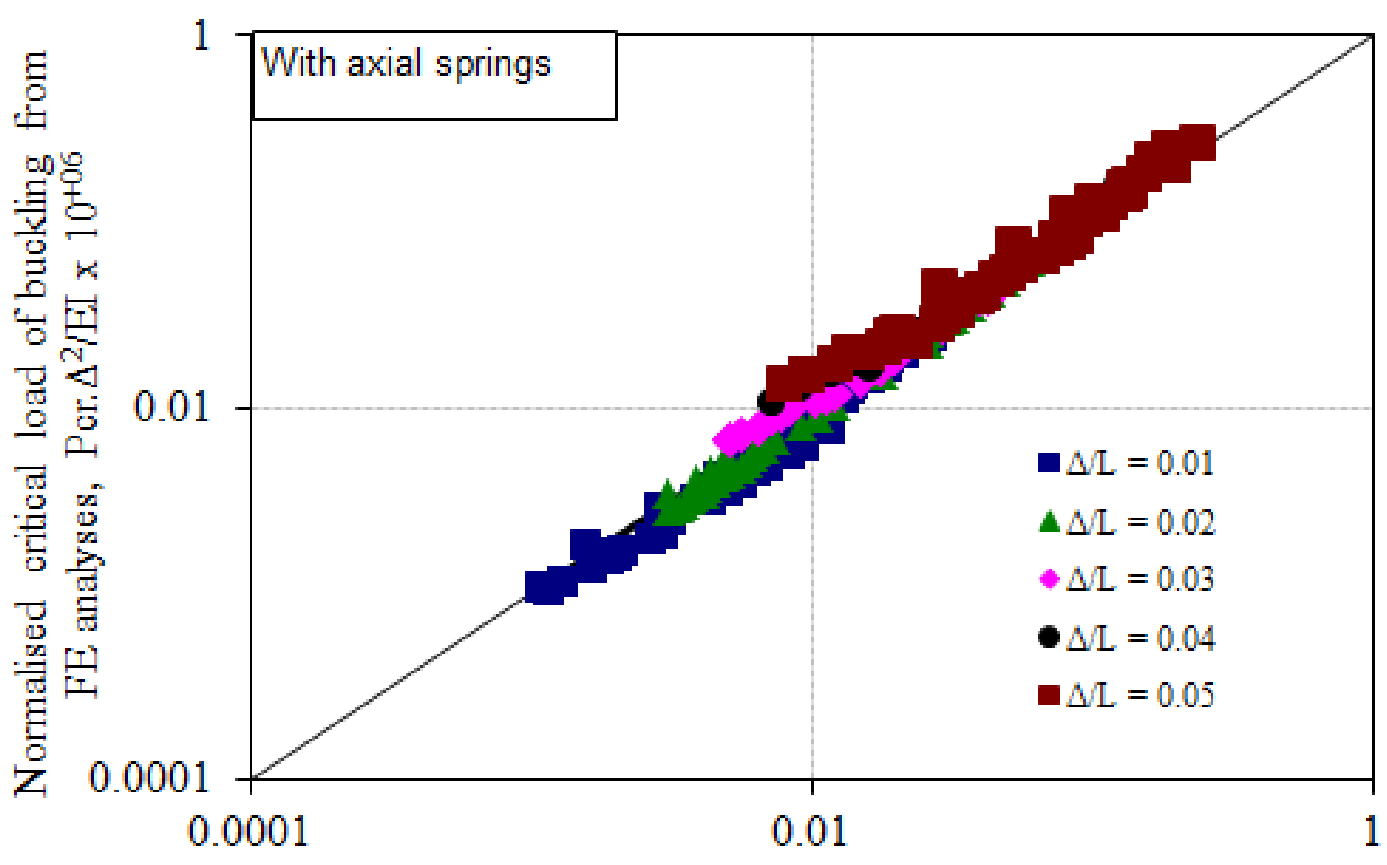

Normalised predicted critical load of buckling, Pcr. $\Delta^{2} / E I \times 10^{+06}$

Figure 14: Multivariate fit to computed critical buckling load with axial spring 


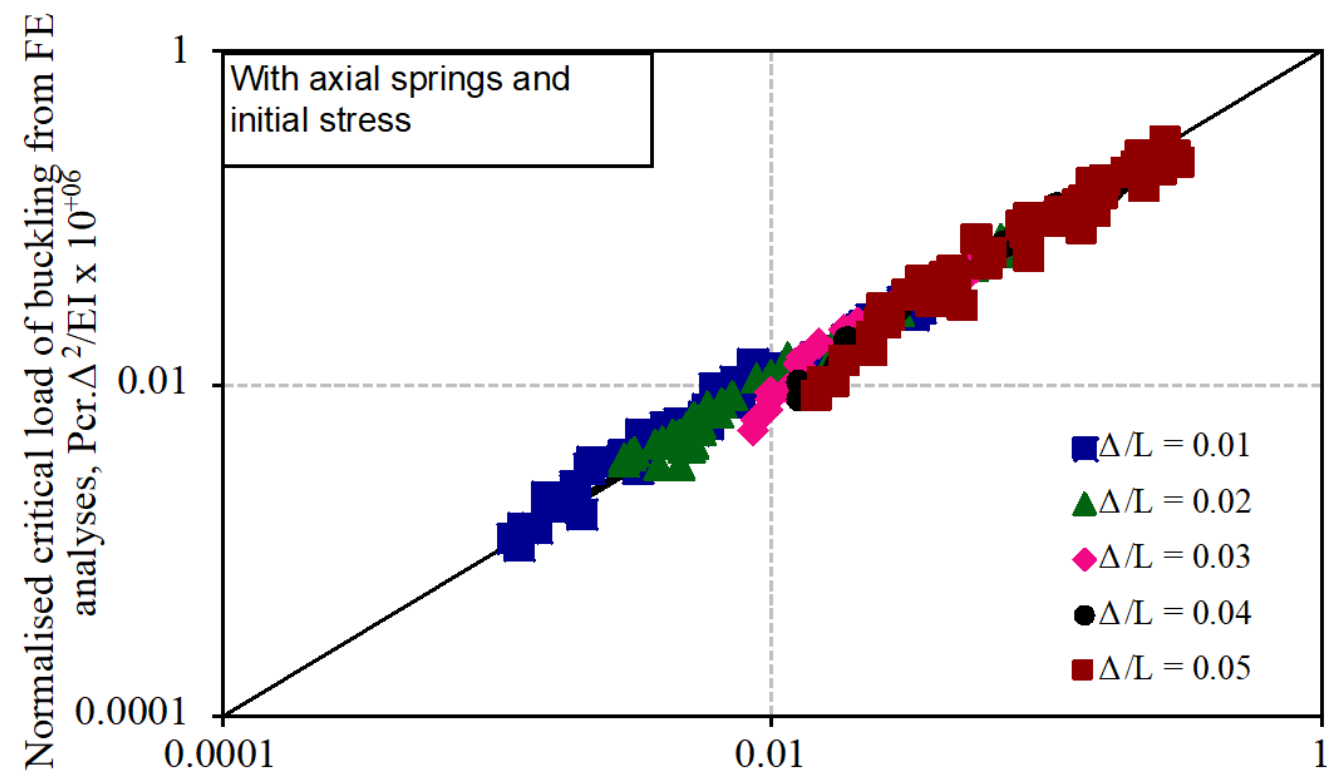

Normalised predicted critical load of buckling, Pcr. $\Delta^{2} / E I \times 10^{+06}$

Figure 15: Multivariate fit to computed critical buckling load with axial spring and initial stress 